Alexandra Fátima Saraiva Soares ${ }^{1}$ Luís Paulo Souza e Souza ${ }^{2}$

\title{
CONTAMINAÇÃO DAS ÁGUAS DE ABASTECIMENTO PÚBLICO POR POLUENTES EMERGENTES E O DIREITO À SAÚDE
}

Contamination of public water supply by emerging pollutants and the right to health

${ }_{1}^{1}$ Ministério Público do Estado de Minas Gerais. Belo Horizonte/MG, Brasil.

${ }^{2}$ Universidade Federal do Amazonas. Instituto de Saúde e Biotecnologia. Departamento de Medicina. Coari/AM, Brasil.

Correspondência: Alexandra Fátima Saraiva Soares. E-mail: alexandra@mpmg.mp.br

Recebido: 18/03/2018. Revisado: 01/02/2019. Aprovado: 15/04/2019. 


\section{RESUMO}

Poluentes emergentes são substâncias com potencial para causar câncer e infertilidade humana, mas seu monitoramento em águas de abastecimento público ainda é incipiente no Brasil. Corpos d'água contaminados podem se tornar mananciais de abastecimento público e técnicas convencionais para tratamento de esgoto e potabilização da água não são adequadas para propiciar a remoção desses poluentes emergentes, também denominados micropoluentes. Este trabalho objetiva discutir as vias de introdução dos micropoluentes nas águas de abastecimento público, as consequências dessas substâncias na saúde humana e os principais instrumentos jurídicos do Direito Sanitário que, se bem aplicados, podem contribuir para minimizar os danos à saúde coletiva decorrentes desses contaminantes. Trata-se de levantamento bibliográfico em livros, periódicos, banco de dados de instituições públicas, legislação e outras fontes pertinentes. Compreender as relações entre os determinantes socioambientais e a degradação da qualidade da água é de grande relevância para intervir na melhoria das condições de vida e de saúde da população em condições vulneráveis. Observou-se que o arcabouço normativo para tutelar o direito à água é vasto e deve ser mais bem considerado pelo poder público (Estado), impondo regras de conduta, e pela sociedade civil, monitorando o cumprimento das regras estabelecidas, de forma a preservar a qualidade ambiental e proteger a saúde da população, garantindo o direito à água de qualidade.

\section{Palavras-Chave:}

Abastecimento de Água; Determinantes Sociais da Saúde; Direito Sanitário; Micropoluentes; Saúde Ambiental.

\section{ABSTRACT}

Emerging pollutants are substances with potential to cause cancer and human infertility. However, the monitoring of these substances in the public water supply is still incipient in Brazil. Contaminated bodies of water often become public sources of supply, and conventional techniques for sewage and water treatment are not adequate to remove these emerging pollutants also called micropollutants. The aim of this paper is to discuss routes of introduction of micropollutants in water for public supply, the consequences of such substances on human health, and the main legal instruments of the Health Law that, if well applied, can help to minimize damages to public health caused by these contaminants. This is achieved with bibliographic survey of books, journals, public institutions' databases, legislation and other relevant sources. Understanding the relationships between the social and environmental determinants and the degradation of the quality of water is of great importance to promote the improvement of living conditions and health of vulnerable populations. Observation shows that the regulatory framework to protect the right to water is wide and should be considered by the state government for imposing rules of conduct, and by civil society for monitoring compliance with the rules laid down in order to preserve the quality of the environment and protect public health, guaranteeing the right to good quality water.

\section{Keywords:}

Water Supply; Social Determinants of Health; Health Law; Micropollutants; Environmental Health. 


\section{Introdução}

No Brasil, a água é considerada potável se atender aos requisitos estabelecidos no Anexo XX - Do controle e da vigilância da qualidade da água para consumo humano e seu padrão de potabilidade, da Portaria de Consolidação n. 5/2017 do Ministério da Saúde ${ }^{1}$. No entanto, essa norma relaciona poucos parâmetros para as denominações "poluentes emergentes" e "micropoluentes". Essas substâncias são denominadas "emergentes" pelo fato de sua presença ter sido descoberta no ambiente apenas nos últimos anos, o que ocorreu devido às melhorias das técnicas analíticas.

Assim, uma água considerada potável pode apresentar contaminação por substâncias ainda não legisladas, mas que podem ser potencialmente nocivas à saúde humana, mesmo em baixas concentrações. Exemplos desses contaminantes são agrotóxicos, fármacos (medicamentos), hormônios, produtos de higiene pessoal e de limpeza e diversos outros produtos químicos, muitos deles presentes nos esgotos domésticos. Há, também, que se ressaltar a dificuldade de detecção e quantificação desses contaminantes nas águas, por ocorrerem em baixas concentrações e devido à complexidade das técnicas analíticas, as quais devem ser sensíveis o suficiente para determinar a presença dessas substâncias de maneira consistente $e^{2,3,4,5}$.

Cabe esclarecer que as tecnologias convencionais de tratamento de esgoto e água para potabilização, normalmente utilizadas no país, não são adequadas para remover os poluentes emergentes ${ }^{6,7,8,9,10,11}$. Dessa forma, o lançamento de esgotos

\footnotetext{
${ }^{1}$ Anexo XX, originário da Portaria MS/GM n. 2.914/2011. (MINISTÉRIO DA SAÚDE - MS. Portaria de Consolidação MS n. 5, de 3 de outubro de 2017. Consolidação das normas sobre as ações e os serviços de saúde do Sistema Único de Saúde. Disponível em: https://portalarquivos2.saude.gov.br/images/pdf/2018/ marco/29/PRC-5-Portaria-de-Consolida--o-n--5-de-28-de-setembro-de-2017.pdf. Acesso em: 18 fev. 2020.) ${ }^{2}$ STACKELBERG, Paul E.et al. Efficiency of conventional drinking-water-treatment processes in removal of pharmaceuticals and other organic compounds. Science of the Total Environment, v. 377, n. 2-3, p. 255272, May 2007. https://doi.org/10.1016/j.scitotenv.2007.01.095.

${ }^{3}$ THUY, Pham Thi etal. To what extentare pesticides removed from surface water during coagulation-flocculation? Water and Environment Journal, v. 22, n. 3, p. 217-223, Jul. 2008. https://doi.org/10.1111/j.1747-6593.2008.00128.x.

${ }^{4} \mathrm{LUO}$, Yun long et al. A review on the occurrence of micropollutants in the aquatic environment and their fate and removal during wastewater treatment. Science of the Total Environment, v. 473-474, p. 619-641, Mar. 2014. https://doi.org/10.1016/j.scitotenv.2013.12.065.

${ }^{5}$ SOARES, Alexandra F. Saraiva. Impacto do uso de agrotóxicos na qualidade da água: estudo de caso em região produtora de café. 1. ed. Novas Edições Acadêmicas, 2015.

${ }^{6}$ STACKELBERG, Paul E.et al. op. cit., p. 255-272.

${ }^{7}$ THUY, Pham Thi et al. op. cit., p. 217-223.

8SOARES, Alexandra F. Saraiva et al. Efficiency of conventional drinking water treatment process in the removal of endosulfan, ethylenethiourea, and 1,2,4-triazole. Journal of Water Supply: Research and Technology-AQUA, v. 62, n. 6, p. 367-376, Sept. 2013. https://doi.org/10.2166/aqua.2013.042.

${ }^{9}$ Id. Ibid.

${ }^{10}$ SILVA, Larissa L.; MOREIRA, Carolina G.; CURZIO, Bianca A.; FONSECA, Fabiana V. Micropollutant removal from water by membrane and advanced oxidation processes: a review. Journal of Water Resource and Protection, v. 9, n. 5, p. 411-431, abr. 2017. Disponivel em: https://www.scirp.org/pdf/JWARP_2017041715102681. pdf. https://doi.org/10.4236/jwarp.2017.95027.

${ }^{11}$ BILGEHAN, Nas; TAYLAN, Dolu; HAVVA, Ates; ARGUN, M. Emim; YEL, Esra. Treatment alternatives for micropollutant removal in wastewater. University Selcuk Journal of Engineering, Science and Technology, v. 5, n. 2, p. 133-143, feb. 2017. Disponivel em: https://www.researchgate.net/publication/319612877_TREATMENT_ALTERNATIVES_ FOR_MICROPOLLUTANT_REMOVAL_IN_WASTEWATER. https://doi.org/10.15317/Scitech.2017.77.
} 
domésticos e efluentes industriais nos corpos d’água, mesmo após tratamento convencional, eleva as concentrações desses poluentes nos ecossistemas aquáticos e pode ocasionar danos ambientais e à saúde.

Sabe-se que as águas superficiais enquadradas a partir da Classe 1, segundo a norma pertinente, podem receber efluentes líquidos e também constituírem mananciais de abastecimento público. No caso do uso de águas dessa classificação, a legislação exige apenas tratamento simplificado antes da distribuição, que consiste na clarificação por meio somente de filtração e desinfecção ${ }^{12}$. Ademais, a água que é distribuída à população brasileira é submetida a uma norma de potabilidade limitada no que concerne a padrões para os poluentes emergentes (Portaria de Consolidação MS n. 5/2017, Anexo XX).

Com isso, a água pode atender aos requisitos da portaria de potabilidade, isto é, ser considerada potável, e não estar isenta de substâncias maléficas à saúde, podendo ocasionar dano futuro advindo de seu consumo.

Estudos sugerem que possíveis alterações na saúde humana - envolvendo câncer de mama e de testículo, além de infertilidade masculina - podem estar relacionadas à exposição a poluentes emergentes ${ }^{13,14,15}$. A presença desses contaminantes em sistemas hídricos tem sido objeto de estudos em diversas partes do mundo onde se discutem os critérios para regulamentação. Assim, e de forma a contribuir para a qualidade da água e melhores condições de saúde à população, ações do poder público e da coletividade devem ser efetivadas e, nesse aspecto, os instrumentos jurídicos têm notória relevância.

Acredita-se numa interface entre o Direito Ambiental e Sanitário (que trata do direito à saúde). Ambos constituem ramos autônomos do direito, vez que dispõem de regras e princípios próprios, isto é, possuem regimes jurídicos específicos ${ }^{16}$. Ademais, uma ciência tem relação direta com a outra, já que as intervenções no meio ambiente terão reflexos nas condições sanitárias dos recursos hídricos e, por consequência, na saúde das pessoas.

\footnotetext{
${ }^{12}$ CONSELHO NACIONAL DO MEIO AMBIENTE - CONAMA. Resolução n. 357, de 17 de março de 2005. Dispõe sobre a classificação dos corpos de água e diretrizes ambientais para o seu enquadramento, bem como estabelece as condições e padrões de lançamento de efluentes, e dá outras providências. Disponível em: http://www2.mma.gov.br/port/conama/legiabre.cfm?codlegi=459. Acesso em: 18 fev. 2020.

${ }^{13}$ GHISELLI, Gislaine; JARDIM, Wilson F. Interferentes endócrinos no ambiente. Química Nova, São Paulo, v. 30, n. 3, p. 695-706, jun. 2007. Disponível em: http://www.scielo.br/pdf/qn/v30n3/31.pdf. https://doi. org/10.1590/S0100-40422007000300032.

${ }^{14}$ LUO, Yun long et al. op. cit., p. 619-641.

${ }^{15}$ SILVA, Larissa L.; MOREIRA, Carolina G.; CURZIO, Bianca A.; FONSECA, Fabiana V. op. cit.,p. 411-431.

${ }^{16} \mathrm{AITH}$, Fernando Mussa Abujamra. Curso de direito sanitário: a proteção do direito à saúde no Brasil. São Paulo: Quartier Latin, 2007.
} 
O Direito Sanitário vem sendo reconhecido como o conjunto de normas jurídicas que estabelecem direitos e obrigações em matéria de saúde para o Estado e indivíduos, regulando de forma ordenada as relações entre eles no interesse da coletividade $^{17}$. Esse ramo da ciência jurídica coordena as diferentes normas do Estado que visam à tutela da "saúde pública".

Uma pessoa poderá ser prejudicada em sua saúde por diferentes formas de agressão advindas da coletividade ou mesmo da má qualidade ambiental, por ação ou omissão, inclusive de entes públicos. Nesse sentido, saúde é um direito fundamental do cidadão, que gera - para o Estado e para a coletividade - obrigações e deveres de participação. Nesse contexto, ensina Aith ${ }^{18}$ que o Direito Sanitário disciplina as ações e os serviços públicos e privados de interesse à saúde, de forma a estabelecer condições que assegurem o acesso universal e igualitário da prestação desses serviços à população.

Assim, este artigo objetiva apresentar discussão acerca das vias de introdução desses micropoluentes nas águas de abastecimento público, as consequências dessas substâncias na saúde humana e os principais instrumentos jurídicos do Direito Sanitário que, se bem aplicados, podem contribuir para minimizar os danos à saúde coletiva decorrentes desses contaminantes.

Trata-se de pesquisa qualitativa, exploratória, realizada mediante levantamento bibliográfico. A busca ocorreu entre janeiro e março de 2018, tendo sido reavaliada em janeiro de 2019 e março de 2020, utilizando livros impressos e digitais, periódicos científicos virtuais, banco de dados de instituições públicas, legislação e outras fontes pertinentes.

Para acesso às bases científicas de dados, realizaram-se buscas na Biblioteca Virtual em Saúde (BVS) com descritores controlados e não controlados para atender ao objetivo deste estudo. Os descritores controlados foram termos registrados nos Descritores em Ciências da Saúde (DeCS) e no sistema Medical Subject Headings (MeSH), que são utilizados para indexação de artigos nas bases de dados. Já os nãos controlados foram palavras ou sinônimos cuja grafia e cujo significado representassem o assunto a ser pesquisado, mas que não são utilizados para indexação dos artigos - portanto, não se encontram registrados nas classificações dos vocabulários DeCS e MeSH - e, ainda assim, viabilizariam a busca e proporcionariam o refinamento do material escolhido ${ }^{19}$. Os descritores controlados

\footnotetext{
${ }^{17}$ AITH, Fernando Mussa Abujamra. op. cit.

${ }^{18}$ Id. Ibid.

${ }^{19}$ SANTOS, Cristina Mamédio da Costa; PIMENTA, Cibele Andrucioli de Mattos; NOBRE, Moacyr Roberto Cuce. A estratégia PICO para a construção da pergunta de pesquisa e busca de evidências. Rev. Latino-Am. Enfermagem, Ribeirão Preto, v. 15, n. 3, p. 508-511, jun. 2007. Disponível em: http://www.scielo.br/pdf/rlae/v15n3/pt_v15n3a23.pdf. 11692007000300023.
} 
utilizados foram "direito sanitário" (health law), "saúde ambiental" (environmental health), "determinantes sociais da saúde" (social determinants of health), "abastecimento de água" (water supply) e "poluentes da água" (water pollutants); já os descritores não controlados foram "micropoluente" (micropollutant), "poluentes emergentes" (emerging pollutants), "contaminação de mananciais" (contamination of water sources) e "tratamento convencional de água" (conventional water treatment). Procedeu-se o cruzamento dos descritores, com "AND" como operador booleano. Para seleção dos textos, adotaram-se os seguintes critérios: artigos, teses e dissertações; disponibilizados eletronicamente na íntegra e de forma gratuita; e que abordassem as fontes dos micropoluentes nas águas, os determinantes sociais da saúde, a eficiência dos tratamentos de água para potabilização no que tange à remoção desses micropoluentes e legislação específica e não específica de Direito Sanitário.

Além da procura na BVS, foram realizadas buscas nos sites: do Planalto do Governo Brasileiro [http://www2.planalto.gov.br]; da Organização Mundial da Saúde (OMS) [https://www.who.int/]; da Comissão Interamericana de Direitos Humanos (CIDH) [http://www.oas.org/pt/cidh/],para acesso à legislação específica; e no portal do Centro de Estudos e Pesquisas de Direito Sanitário (Cepedisa) da Universidade de São Paulo (USP) [http://napdisa.prp.usp.br/], para acesso a documentos pertinentes ao tema ou a elementos que direcionassem as buscas em outras fontes. Destaca-se que livros impressos e digitais sobre a temática também foram utilizados.

As informações extraídas dos materiais/textos foram organizadas de forma descritiva em tópicos e, posteriormente, elaborou-se o modelo "Pressão-Estado-Resposta" para o caso em tela (Figura 5), visando a demonstrar de maneira sucinta como ocorre a contaminação da água por micropoluentes e suas consequências à saúde das populações humanas. A análise da regulamentação existente no controle da contaminação hídrica no âmbito do Direito Sanitário foi apresentada ao final (Tópico V e Quadro 1), para que o leitor possa conhecer os principais instrumentos jurídicos existentes e refletir acerca da pertinência/abrangência da legislação posta, além de, eventualmente, contribuir para aprimorá-la e mitigar os danos à saúde pública.

\section{Fontes de micropoluentes na água}

As fontes de micropoluentes nos recursos hídricos são diversas, sendo que muitos desses contaminantes originam-se de produtos industrializados. A Figura 1 apresenta algumas fontes de micropoluentes nos ambientes aquáticos. 


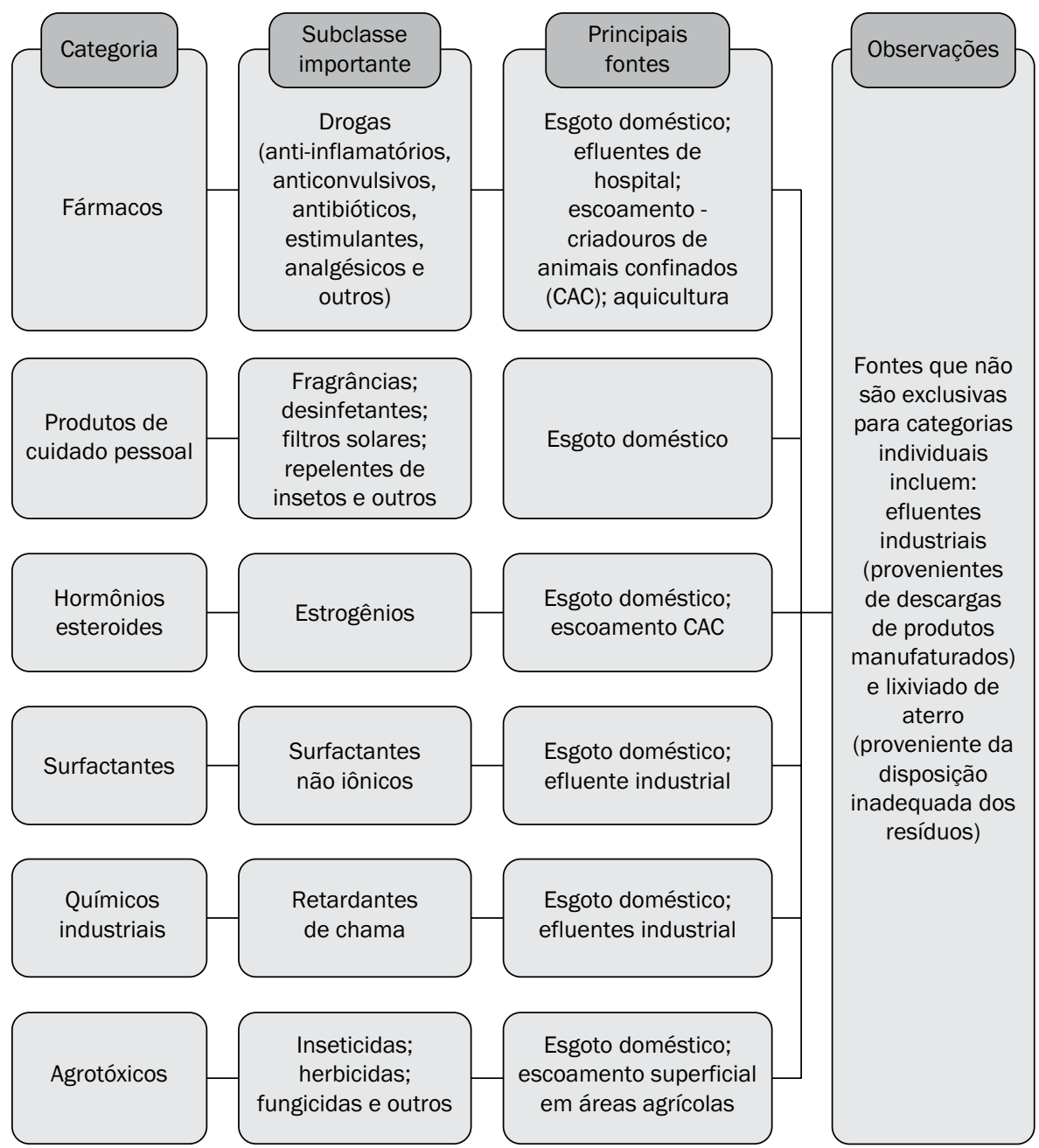

Fonte: Adaptado de Luo et al. $(2014)^{20}$.

Figura 1. Fontes de micropoluentes em ambientes aquáticos

Mais de 100.000 compostos químicos sintéticos são utilizados em uma grande variedade de produtos de uso doméstico, industrial e agrícola, e atingem as 
águas superficiais por lançamento de água residuária ou carreamento (escoamento superficial proveniente de áreas agrícolas com aplicação de agrotóxicos) ${ }^{21}$.

Em 2001, a União Europeia 22 elegeu 33 compostos orgânicos como prioritários no controle de poluição da água, sendo a maior parte micropoluente. Desde então, vários projetos vêm sendo desenvolvidos, buscando alternativas para que sejam atendidos os padrões de qualidade de água relativos a esses compostos, cada vez mais restritivos.

\section{Agrotóxicos}

Os agrotóxicos têm sido utilizados extensamente em todo o mundo, e a poluição ambiental decorrente desses poluentes constitui problema em escala global. O mercado de agrotóxicos tem característica de oligopólio - em 2007, seis empresas concentravam $86 \%$ das vendas mundiais desses produtos ${ }^{23}$.

No Brasil, diversos estados (MG, SP, PE, PR, ES, CE e RJ $)^{24}$ possuem políticas de incentivo à comercialização desses agroquímicos, com reduções significativas de Imposto sobre Circulação de Mercadorias e Prestação de Serviços (ICMS), que podem alcançar, em determinadas épocas ou períodos, $100 \%{ }^{25}$.

De acordo com o Sindicato Nacional da Indústria de Produtos para Defesa Vegetal (Sindiveg), o Brasil é um dos maiores consumidores de agrotóxicos do mundo ${ }^{26}$. O consumo nacional de agrotóxicos e afins por área plantada mais do que

${ }^{21}$ HALLING-SORENSEN, B. et al. Occurrence, fate and effects of pharmaceutical substances in the environment - A review. Chemosphere, v.36, n. 2, p. 357-393, Jan. 1998. https://doi.org/10.1016/S00456535(97)00354-8.

${ }^{22}$ EUROPEAN UNION. Decision $n^{\circ} 2.455 / 2001 / E C$ of the European Parlament and of the Council of 20 November 2001 establishing the list of priority substances in the field of water policy and amending, Directive 2000/60/EC. Official Journal of the European Union, L331/1-L331/5, 2001. Disponivel em: https://eur-lex. europa.eu/LexUriServ/LexUriServ.do?uri=OJ:L:2001:331:0001:0005:EN:PDF. Acesso em: 18 fev. 2020.

${ }^{23}$ LONDRES, Flavia. Agrotóxicos no Brasil: um guia para ação em defesa da vida. Rio de Janeiro: Assessoria e Serviços a Projetos em Agricultura Alternativa, 2011.

${ }^{24}$ MINAS GERAIS (Estado). Decreto n. 43.080, de 13 de dezembro de 2002. Disponível em: http://www. fazenda.mg.gov.br/empresas/legislacao_tributaria/decretos/d43080_2002.htm. Acesso em 18.02.2020; SÃO PAULO (Estado). Decreto n. 45.490, de 30 de novembro de 2000. Disponível em: https://www.al.sp. gov.br/repositorio/legislacao/decreto/2000/decreto-45490-30.11.2000.html. Acesso em 18.02.2020; PERNAMBUCO (Estado). Decreto n. 14.876, de 14 de março de 1991. Disponível em: https://www.sefaz. pe.gov.br/Legislacao/Tributaria/Documents/legislacao/14876/livros/Livro1_Art_1a13.htm. Acesso em: 18 fev. 2020; PARANÁ (Estado). Decreto n. 1980, de 21 de dezembro de 2007. Disponível em: http:// www.sefanet.pr.gov.br/SEFADocumento/Arquivos/6200701980.pdf. Acesso em: 18 fev. 2020; ESPÍRITO SANTO (Estado). Decreto n. 1090, de 25 de outubro de 2002. Disponível em: http://www.sefaz.es.gov. $\mathrm{br} /$ legislacaoonline/Ipext.dll/InfobaseLegislacaoOnline/ricms\%20-\%20dec\%201090-r/ricms\%20-\%20 \%EDndice.htm. Acesso em: 18 fev. 2020; RIO GRANDE DO NORTE (Estado). Decreto n. 13.640, de 13 de novembro de 1997. Disponível em: https://www.legisweb.com.br/legislacao/?id=152481. Acesso em: 18 fev. 2020; CEARÁ (Estado). Decreto n. 33.327, de 30 de outubro de 2019. Disponível em: https://www. legisweb.com.br/legislacao/?id=384287. Acesso em: 18 fev. 2020.

${ }^{25}$ SOARES, Alexandra F. Saraiva. Impacto do uso de agrotóxicos na qualidade da água: estudo de caso em região produtora de café, cit.

${ }^{26}$ MOTTA, Débora. Portal reúne dados sobre agrotóxicos no País. Fundação de Amparo à Pesquisa do Estado do Rio de Janeiro-FAPERJ, 25 ago. 2016. Disponível em: http://www.faperj.br/?id=3222.2.2. Acesso em: 25 dez. 2018. 
dobrou em 14 anos, saltando de 3,20 quilogramas por hectare em 2000 para $6,9 \mathrm{~kg} /$ ha em 2012 e 6,7 kg/ha em 2014, de acordo com Instituto Brasileiro de Geografia e Estatística (IBGE) ${ }^{27}$. Relatório de registros de novos agrotóxicos divulgado pelo Ministério da Agricultura, Pecuária e Abastecimento (MAPA) ${ }^{28}$ indicou que, até julho de 2017, foram registradas 183 novas substâncias, equivalentes a um aumento de $177 \%$ em comparação ao mesmo período de 2016 . O número de agrotóxicos liberados, para uso em lavouras brasileiras em 2019, foi o maior dos últimos dez anos. Entre o dia $1^{\circ}$ de janeiro e 27 de dezembro de 2019, foi aprovada a utilização de 474 novos produtos ${ }^{29}$, superando o recorde de 2018, quando foram liberados 422 agrotóxicos em 12 meses. Trata-se, portanto, de um mercado em expansão.

Em 2016, a dinamarquesa Julie Hjerl Hansen, em visita ao sul de Minas Gerais, publicou pelo Danwatch - centro de pesquisa e mídia da Dinamarca, especializado em jornalismo investigativo sobre questões globais como impactos nos direitos humanos e no meio ambiente - um documento com diagnóstico do uso de agrotóxicos nas lavouras de café. Foi demonstrado que, no Brasil, o café pode ser pulverizado com agrotóxicos ilegais na União Europeia (UE), assim considerados por serem extremamente tóxicos e causarem doenças. Segundo o relatório, muitos trabalhadores brasileiros aplicam agrotóxicos sem o uso adequado de equipamento de proteção, e o envenenamento de seres humanos por essas substâncias é generalizado. Até mesmo a água potável distribuída para abastecimento público contém resíduos de agrotóxicos perigosos. Ademais, o documento contém relatos de pessoas da região que, por exemplo, reutilizam embalagens de agrotóxicos para armazenar água e alimento ${ }^{30}$. O Danwatch também teve acesso a um banco de dados compilado pelas autoridades brasileiras acerca das lavouras de café em Minas Gerais, com informações sobre as vendas de agrotóxicos. Muitas das substâncias utilizadas apresentaram potencial para causar dano tanto a insetos quanto aos seres humanos. O documento relata que pesquisadores suspeitam de que as substâncias danifiquem os sistemas reprodutivos humanos e causem, também nos seres humanos, sintomas semelhantes aos da doença de Parkinson, como problemas de coordenação e tremores.

\footnotetext{
${ }^{27}$ INSTITUTO BRASILEIRO DE GEOGRAFIA E ESTATÍSTICA - IBGE. Uso de Agrotóxicos - 1 Consumo nacional de agrotóxicos e afins por área plantada. Período:2000-2014. (Séries históricas e estatísticas). Disponível em: https://seriesestatisticas.ibge.gov.br/series.aspx?vcodigo=IU18\&t=uso-agrotoxicos-1-consumo-nacionalagrotoxicos. Acesso em: 25 dez. 2018.

${ }^{28}$ MINISTÉRIO DA AGRICULTURA, PECUÁRIA E ABASTECIMENTO - MAPA. Agrotóxicos, 2017. Disponível em: http://www.agricultura.gov.br/assuntos/insumos-agropecuarios/insumos-agricolas/agrotoxicos. Acesso em: 22 out. 2017.

${ }^{29}$ MINISTÉRIO DA AGRICULTURA, PECUÁRIA E ABASTECIMENTO - MAPA. Defensivos agrícolas. Em 2019, $94,5 \%$ dos defensivos agrícolas registrados foram produtos genéricos. Disponível em: http://www. agricultura.gov.br/noticias/defensivos-agricolas. Acesso em: 26 mar. 2020.

${ }^{30}$ HANSEN, Julie Hjerl. Brazilian coffee is sprayed with deadly pesticides. Danwatch, 10 Mar. 2016. Disponível em: https://old.danwatch.dk/en/nyhed/brasiliansk-kaffe-sproejtes-med-livsfarlige-pesticider/. Acesso em: 25 dez. 2018.
} 
Além de entrevistas com trabalhadores do setor cafeeiro, especialistas e funcionários de sindicatos, Julie Hansen consultou o banco de dados do MAPA para conhecer os agrotóxicos aprovados para cultivo de café no Brasil ${ }^{31}$. Em seguida, ela comparou os ingredientes ativos dessas substâncias com os pesticidas aprovados pela UE. Concluiu que muitos dos agrotóxicos amplamente utilizados nas plantações brasileiras de café são classificados pela UE como extremamente tóxicos aos seres vivos e, portanto, de uso proibido ${ }^{32}$. Os dinamarqueses têm interesse em conhecer o ambiente onde o café consumido por eles é produzido. Sabe-se que a questão ambiental é globalizada.

No meio ambiente, o transporte e a redeposição de agrotóxicos podem ocorrer a longas distâncias, causados por movimentos atmosféricos. Exemplo disso foi a constatação de agrotóxicos organoclorados em neblinas sobre o oceano no Canadá, relatada por Gregor e Gummer ${ }^{33}$; e na neve do Ártico, relatada por Schomburg e Glotfelty ${ }^{34}$. Assim, a contaminação ambiental por agrotóxicos deve ser analisada globalmente, vez que não consiste em poluição pontual.

Ferreira $^{35}$ defende a proibição da pulverização aérea de agrotóxicos em todo o território nacional, como já ocorre em Nova Venécia e Vila Valerio, ambos municípios do Espírito Santo. A contaminação da água por agrotóxicos pode ocorrer diretamente pela deriva das pulverizações aéreas e indiretamente pela erosão dos solos contaminados, pelo escoamento superficial (runoff, ou enxurrada) e pela lixiviação, e, ainda, pelo descarte e lavagem de tanques e embalagens de produtos ${ }^{36}$.

É preciso reforçar também a importância da manutenção da vegetação das áreas de preservação permanente (APP), estabelecidas no Código Florestal Brasileiro, para reduzir a contaminação das águas. Essas áreas de preservação contribuem para reduzir o carreamento do agrotóxico associado ao solo pelas enxurradas ${ }^{37}$. Águas superficiais contaminadas podem ter efeitos ecotoxicológicos para a fauna e a flora aquáticas, e para a saúde humana quando utilizadas

\footnotetext{
${ }^{31}$ SISTEMAS DE AGROTÓXICOS FITOSSANITÁRIOS - AGROFIT. Consulta de Produtos Formulados. Disponível em: http://agrofit.agricultura.gov.br/agrofit_cons/principal_agrofit_cons. Acesso em: 25 dez. 2018.

${ }^{32}$ HANSEN, Julie Hjerl. op. cit.

${ }^{33}$ GREGOR, D. J.; GUMMER, W. D. Evidence of atmospheric transport and deposition of organochlorine pesticides and polychlorinated biphenyls in Canadian artic snow. Environ. Sci. Technol., v. 23, n. 5, p. 561565, May 1989. https://doi.org/10.1021/es00063a008.

${ }^{34}$ SCHOMBURG, C.J.; GLOTFLELTY, D.E. Pesticide occurrence and distribution in fog collected near Monterey, California. Environ. Sci. Technol., v. 25, n. 1, p. 155-160, Jan. 1991. https://doi.org/10.1021/es00013a018.

${ }^{35}$ FERREIRA, Maria Leonor Paes Cavalcanti. A pulverização aérea de agrotóxicos no Brasil: cenário atual e desafios. Revista de Direito Sanitário, São Paulo, v. 15, n. 3, p. 18-45, 14 abr. 2015. Disponível em: http:// www.revistas.usp.br/rdisan/article/view/97324/96336. https://doi.org/10.11606/issn.2316-9044. v15i3p18-45.

${ }^{36}$ SOARES, Alexandra F. Saraiva. Pesticides environmental destination: a study based on coffee productive areas. Belo Horizonte: Editor: Tiago Silveira Gontijo, 2018.

${ }^{37}$ SOARES, Alexandra F. Saraiva et al. Risk estimate of water contamination by pesticides used in coffee crops. Rev. bras. eng. agríc. ambient., Campina Grande, v. 16, n. 4, p. 425-432, abr. 2012. Disponível em: http:// www.scielo.br/pdf/rbeaa/v16n4/v16n04a13.pdf. https://doi.org/10.1590/S1415-43662012000400013.
} 
para abastecimento público. Isso porque esses produtos são geralmente tóxicos para organismos, muitos são dificilmente degradados no ambiente e apresentam efeitos bioacumulativos.

\section{Esgotos domésticos}

O lançamento de esgoto - in natura ou mesmo proveniente de estações de tratamento biológico, principalmente sistemas anaeróbios - nas águas superficiais (córregos, rios e outros) tem sido considerado como principal fonte de micropoluentes no ambiente aquático ${ }^{38}$.

Luo et al. ${ }^{39}$, comparando a ocorrência de micropoluentes nas águas superficiais de diferentes países, relataram que, em geral, a poluição de contaminantes emergentes nos corpos d'água das regiões densamente povoadas é maior, devido ao uso massivo desses contaminantes pela população e consequente composição do esgoto doméstico.

O consumo de produtos contendo micropoluentes determina a variedade e quantidade desses contaminantes que alcança as estações de tratamento. Zhang, Geissen e Gal ${ }^{40}$ indicaram que o consumo per capita anual de fármacos no mundo é de cerca de 15 gramas, mas que países desenvolvidos consomem de três a 10 vezes mais ( 45 a 150 gramas). Assim, pode-se esperar que o esgoto bruto nos países desenvolvidos apresente maior concentração desses contaminantes.

Fármacos ingeridos oralmente e contendo contaminantes potenciais são metabolizados no corpo humano e, consequentemente, excretados via urina e fezes. A elevada taxa de excreção e o uso intensivo desses compostos exercem um papel determinante na introdução de fármacos no esgoto doméstico. Condições climáticas também podem interferir na prevalência de determinadas doenças e, portanto, no consumo de medicamentos e na composição dos efluentes. Outros importantes fatores são chuva, temperatura e incidência solar, pois interferem na diluição e degradação dos compostos na água ${ }^{41}$.

Estações de tratamento de esgotos são projetadas para controlar inúmeros poluentes, tais como partículas, substâncias carbonáceas, nutrientes e patógenos. Enquanto essas substâncias podem ser eficiente e consistentemente removidas da água, a remoção de micropoluentes muitas vezes é insuficiente nesses sistemas

\footnotetext{
${ }^{38}$ KASPRZYK-HORDERN, B.; DINSDALE, R.M.; GUWY, A.J. The removal of pharmaceuticals, personal care products, endocrine disruptors and illicit drugs during wastewater treatment and its impact on the quality of receiving waters. Water Res., v. 43, n. 2, p. 363-380, Feb. 2009. https://doi.org/10.1016/j. watres.2008.10.047.

${ }^{39}$ LUO, Yunlong et al., op. cit., p. 619-641.

${ }^{40}$ ZHANG, Y.; GEISSEN, Sven-Uwe; GAL, Carmen. Carbamazepine and diclofenac: removal in wastewater treatment plants and occurrence in water bodies. Chemosphere, v. 73, n. 8, p. 1151-1161, Nov. 2008.

${ }^{41}$ KASPRZYK-HORDERN, B.; DINSDALE, R.M.; GUWY, A.J. op. cit., p. 363-380.
} 
convencionais ${ }^{42,43,44,45,46}$. Resultados das pesquisas conduzidas por Köck-Schulmeyer et al. $^{47}$ e Luo et al. ${ }^{48}$ indicaram que os antibióticos avaliados apresentaram baixa a moderada remoção (35\% a 64\%) nos tratamentos convencionais. Reguladores de lipídios e betabloqueadores também não foram eficazmente eliminados (37\% a 73\%). Anticonvulsivos foram os fármacos mais persistentes, sendo reduzidos em $32 \% \mathrm{em}$ média. No caso dos produtos de cuidado pessoal, hormônios esteroides e surfactantes foram reveladas reduções relativamente altas (superiores a 70\%). Já os agrotóxicos estudados (de uso doméstico) foram resistentes ao tratamento convencional de esgoto.

As empresas farmacêuticas em Minas Gerais, em geral, aplicam métodos convencionais para tratamento dos efluentes gerados em seus processos, e não há praticamente avaliação sobre a eficiência desses métodos na remoção de resíduos de fármacos (antibióticos, por exemplo). Pesquisa conduzida por Deschamps et al. ${ }^{49}$ revelou que a rota de tratamento convencional adotada por duas empresas farmacêuticas de Minas Gerais não foi suficientemente eficaz, vez que resíduos e fragmentos de antibióticos foram detectados após o tratamento.

Fatores internos (características físico-químicas dos micropoluentes) e externos (características do esgoto e condições de tratamento) governam o destino de micropoluentes nas estações de tratamento de esgoto.

Estudo de Alves et al. ${ }^{50}$ apresentou concentrações para alguns micropoluentes orgânicos constatados em efluentes. Nesse trabalho, menciona-se que a presença dessas substâncias em efluentes de estações de tratamento possuem variações espaciais e temporais significativas, que são explicadas por vários fatores, como práticas e vendas de produtos específicos, metabolismo, consumo per capita de água, tecnologia de tratamento, persistência ambiental e eficiência de remoção no processo de tratamento.

Cabe ressaltar que, atualmente, nenhum tratamento específico está disponível para assegurar a completa remoção de vários micropoluentes, devido à diversidade de

\footnotetext{
${ }^{42}$ CLARA, M. et al. Identification of relevant micropollutants in Austrian municipal wastewater and their behaviour during wastewater treatment. Chemosphere, v. 87, n. 11, p.1265-1272, June 2012. https://doi. org/10.1016/j.chemosphere.2012.01.033.

${ }^{43}$ LUO, Yunlong et al.op. cit.,p. 619-641.

${ }^{44}$ CAMACHO-MUÑOZ, Dolores; MARTIN, Jarolímek; SANTOS, J. L.; ALONSO, E. Effectiveness of conventional and low-cost wastewater treatments in the removal of pharmaceutically active compounds. Water, Air \& Soil Pollution, v. 223, n. 5, p. 2611-2621, Jun. 2012. https://doi.org/10.1007/s11270-011-1053-9.

${ }^{45}$ SILVA, Larissa L.; MOREIRA, Carolina G.; CURZIO, Bianca A.; FONSECA, Fabiana V. op. cit., p. 411-431.

${ }^{46}$ BILGEHAN, Nas; TAYLAN, Dolu; HAVVA, Ates; ARGUN, M. Emim; YEL, Esra., op. cit., p.133-143.

${ }^{47}$ KÖCK-SCHULMEYER, Marianne et al. Occurrence and behavior of pesticides in wastewater treatment plants and their environmental impact. Science of The Total Environment, v. 458-460, p. 466-476, Aug. 2013. https://doi.org/10.1016/j.scitotenv.2013.04.010.

${ }^{48}$ LUO, Yunlong et al.op. cit.,p. 619-641.

${ }^{49}$ DESCHAMPS, E. et al. Management of effluents and waste from pharmaceutical industry in Minas Gerais, Brazil. Braz. J. Pharm. Sci., São Paulo, v. 48, n. 4, p. 727-736, Oct./Dec. 2012. Disponível em: http://www. scielo.br/pdf/bjps/v48n4/v48n4a17.pdf. https://doi.org/10.1590/S1984-82502012000400017.

${ }^{50}$ ALVES, T. C.; GIRARDI, R.; PINHEIRO, A. Micropoluentes orgânicos: ocorrência, remoção e regulamentação. Revista de Gestão de Água da América Latina, v. 14, e1, 2017. 10.21168/rega.v14n0.p0-1.
} 
propriedades dessas substâncias. Ainda estão em desenvolvimento processos confiáveis e capazes de remover os micropoluentes de forma eficaz. Dessa forma, contaminantes emergentes, potencialmente danosos ao ambiente e à saúde mesmo em baixas concentrações, são introduzidos nas águas superficiais pelo esgoto "tratado" nas estações ${ }^{51}$.

Em Minas Gerais, com a publicação da Deliberação Normativa Conjunta do Conselho Estadual de Política Ambiental e do Conselho Estadual de Recursos Hídricos (COPAM/CERH) n. 01/2008 ${ }^{52}$, estações de tratamento de esgoto doméstico menos eficientes foram legalizadas, culminando com o lançamento, em cursos d'água, de esgoto "tratado" com maior concentração de poluentes, o que elevou também a concentração desses micropoluentes nas águas ${ }^{53}$.

Menciona-se, ainda, o fato de muitos corpos de águas receptores de esgoto sem tratamento ou submetidos a tratamento pouco eficiente constituírem também mananciais de abastecimento público de água, como ocorre com o Rio Paraopeba e Rio das Velhas na região metropolitana de Belo Horizonte, por exemplo. Essas águas contaminadas com micropoluentes são submetidas ao tratamento convencional (coagulação-floculação) para potabilização, que não constitui técnica adequada para promover a remoção desses contaminantes, conforme mencionado, colocando em risco a saúde da população abastecida com essas águas.

O Silent Spring Institute, nos Estados Unidos, estuda a qualidade das águas de Cape Cod, Massachusetts, com o objetivo de compreender se há relação entre fatores ambientais e a elevada incidência de câncer de mama na região. Os resultados sugeriram relação entre a exposição a certos micropoluentes (desreguladores endócrinos) e doenças ativas hormonais, tais como o câncer de mama. Foram detectados fármacos e hormônios na água de Cape Cod, especialmente em áreas mais densamente povoadas, indicando o esgoto sanitário (sistema séptico) como fonte desses contaminantes ${ }^{54}$.

Já Kristensenet et al. ${ }^{55}$ demonstraram que analgésicos comuns (acetaminophen) reduzem em 100 vezes a produção de testosterona e relataram problemas de reprodução em meninos cujas mães usaram analgésicos enquanto grávidas.

${ }^{51}$ LUO, Yunlong et al.op. cit.,p. 619-641.

${ }^{52}$ MINAS GERAIS (Estado). Conselho Estadual de Política Ambiental - COPAM. Conselho Estadual de Recursos Hídricos do Estado de Minas Gerais - CERH-MG. Deliberação Normativa Conjunta COPAM/CERH-MG n. 01, de 05 de maio de 2008. Dispõe sobre a classificação dos corpos de água e diretrizes ambientais para o seu enquadramento, bem como estabelece as condições e padrões de lançamento de efluentes, e dá outras providências. Disponível em: http://www.siam.mg.gov.br/sla/download.pdf?idNorma=8151. Acesso em: 18 fev. 2020.

${ }^{53}$ SOARES, Alexandra F. Saraiva; MACHADO, A.O.V.; DINIZ, P.S. Informações técnicas referentes à Deliberação Normativa Conjunta COPAM/CERH-MG No 1, de 5 de maio de 2008. Parecer Técnico. ID SGDP 1011391. 2008. Disponível em: https://intranet.mpmg.mp.br/intranetmpmg/institucional/central-de-apoio-tecnico/ meio-ambiente/. Acesso em: 23 out. 2017.

${ }^{54}$ SCHAIDER, L. et al. Emerging contaminants in Cape Cod private drinking water wells. Reserching the environment and women's health. Silent Spring Institute, 2011. Disponivel em: http://www.silentspring. org/sites/default/files/Emerging-contaminants-private-wells.pdf. Acesso em: 21 mar. 2014.

${ }^{55}$ KRISTENSEN, David Møbjerget al. Intrauterine exposure to mild analgesics is a risk factor for development of male reproductive disorders in human and rat. Human Reproduction, v. 26, n. 1, p. 235-244, Jan. 2011. https://doi.org/10.1093/humrep/deq323. 
Alves et al. ${ }^{56}$ informaram que a exposição humana aos micropoluentes, mesmo em baixas concentrações, pode afetar o sistema endócrino, sendo isso relacionado a doenças como hipo/hipertireoidismo, diabetes, tumores, dentre outras.

Há que se destacar que, enquanto as pessoas estão expostas a complexas misturas de substâncias químicas, a maior parte dos estudos foca um químico de cada vez. Portanto, tem-se limitada compreensão dos potenciais efeitos na saúde das misturas farmacêuticas (efeitos sinérgicos) e de outras substâncias químicas em baixos níveis.

Por fim, pesquisa conduzida por Ghiselli e Jardim ${ }^{57}$ também aponta possíveis alterações na saúde humana - envolvendo câncer de mama e de testículo, além de infertilidade masculina - associadas à exposição aos micropoluentes.

\section{Determinantes Sociais da Saúde (DSS)}

A relação dos determinantes sociais com o processo saúde-doença da população tem ganhado destaque. No entanto, cabe salientar que, desde o Império Romano, a política incluía duas grandes áreas da saúde pública - a higiene do meio ambiente e a ação social, com administração específica voltada para a supervisão das soluções urbanísticas e de abastecimento hídrico das cidades romanas ${ }^{58}$. Assim, há muito tempo, constata-se associação dos fatores sociais e ambientais na saúde, podendo ressaltar o termo "determinantes socioambientais da saúde".

Modelos teórico-conceituais vêm sendo elaborados para explicar como esses determinantes sociais e ambientais geram iniquidades em saúde, de forma a subsidiar ações voltadas para as "causas das causas". Além disso, indicadores relacionados aos diferentes determinantes estão sendo organizados por meio de metodologias que viabilizem análises integradas ${ }^{59}$.Todavia, constata-se que impactos negativos ocasionados ao meio ambiente, como contaminação da água de abastecimento público, têm sido pouco considerados como determinantes ambientais da saúde em conjunto com os sociais.

Em 2005, a Organização Mundial da Saúde (OMS) ${ }^{60}$ criou a Comissão sobre Determinantes Sociais da Saúde (Commissionon Social Determinants of Health $\mathrm{CSDH}$ ), objetivando promover, em âmbito internacional, conscientização sobre a influência dos determinantes sociais na saúde e sobre a necessidade de combater as iniquidades ocasionadas.

\footnotetext{
${ }^{56}$ ALVES, T. C.; GIRARDI, R.; PINHEIRO, A. op. cit.

${ }^{57}$ GHISELLI, Gislaine; JARDIM, Wilson F. op. cit., p. 695-706.

${ }^{58} \mathrm{AITH}$, Fernando Mussa Abujamra. op. cit.

${ }^{59}$ SOBRAL, André; FREITAS, Carlos Machado de. Modelo de organização de indicadores para operacionalização dos determinantes socioambientais da saúde. Saude soc., v. 19, n. 1, p. 35-47, mar. 2010. Disponível em: http://www.scielo.br/pdf/sausoc/v19n1/04.pdf. https://doi.org/10.1590/S010412902010000100004.

${ }^{60}$ WORLD HEALTH ORGANIZATION - WHO. Guidelines for drinking - water quality: recommendations. Second Addendum to Third Edition. Geneva: WHO, 2008. v. 1. Disponível em: http://www.who.int/water_sanitation_ health/dwq/fulltext.pdf. Acesso em: 22 out. 2017.
} 
Sabe-se que essas iniquidades em saúde atingem todos os países e são influenciadas pela política e economia vigentes. Para a CSDH, a ocorrência de doenças relaciona-se com as condições em que as pessoas nascem, vivem e trabalham, ou seja, tem direta correlação com as condições sociais e ambientais, além de fatores econômicos e culturais. Fortalecer a equidade em saúde significa ir além das intervenções concentradas exclusivamente sobre as causas imediatas das doenças ${ }^{61,62}$. A abordagem conceitual adotada pela CSDH baseia-se no modelo de produção social da doença elaborado por Diderichsen e colaboradores ${ }^{63}$, conforme apresentado na Figura 2.

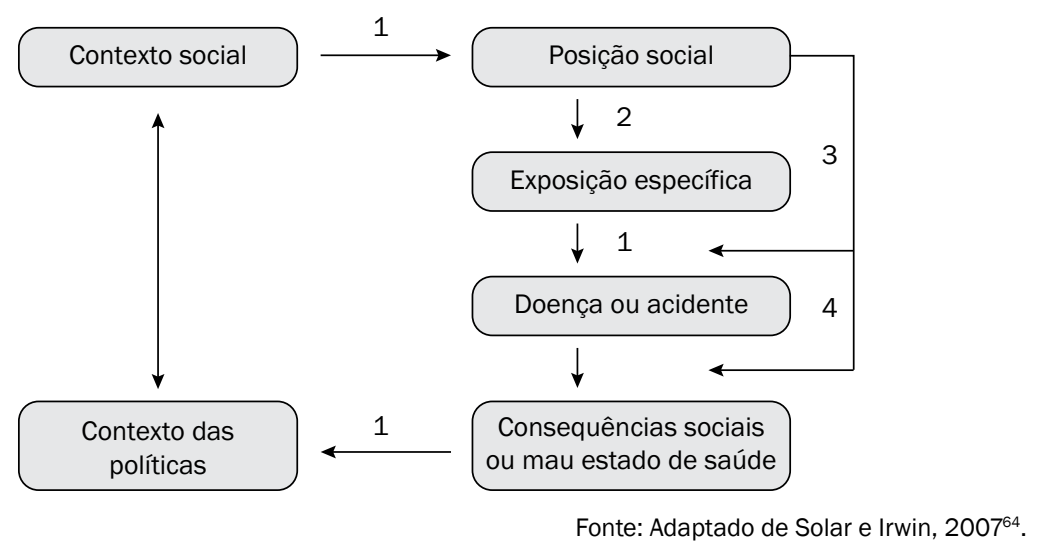

Figura 2. Modelo de produção social da doença

Essa abordagem serviu de base para a proposição de ações voltadas para a "causa das causas", apresentando elementos estruturantes e intervenientes das condições que afetam a saúde dos indivíduos. Os elementos determinam e condicionam as posições sociais ocupadas pelos indivíduos que compartilham características de inserção econômica (ocupação), escolaridade, renda entre outros. Por sua vez, esses elementos que definem os estratos sociais relacionam-se com a vulnerabilidade aos riscos de danos à saúde, na forma de doença ou acidentes, bem como das consequências sociais e o estado de saúde. Assim, os determinantes sociais da saúde e as questões ambientais se inter-relacionam ${ }^{65}$.

\footnotetext{
${ }^{61}$ MARMOT, Michael. Health in an unequal world. The Lancet, v. 368, n. 9552, p. 2081-2094, Dec. 2006.

${ }^{62}$ BARATA, Rita Barradas. Desigualdades sociais e saúde. In: CAMPOS, Gastão Wagner de Sousa. et al. Tratado de saúde coletiva. Rio de Janeiro: Hucitec; Editora Fiocruz, 2006. p. 457-486. p. 457-486.

${ }^{63}$ SOLAR, O.; IRWIN, A. Towards a conceptual framework for analysis and action on the social determinants of health. Geneva: WHO Commission on Social Determinants of Health, 2007. (Discussion Paper Series on Social Determinants of Health, 2).

${ }^{64}$ Id. Ibid.

${ }^{65}$ SOBRAL, André; FREITAS, Carlos Machado de. op. cit., p. 35-47.
} 
O impacto que a doença pode causar sobre a situação socioeconômica do indivíduo e sua família consiste nas denominadas "consequências sociais"66.

O Brasil foi o primeiro membro da OMS a criar, em 2006, Comissão Nacional sobre Determinantes Sociais da Saúde (CNDSS). Os objetivos estabelecidos pela CNDSS incluem: produzir informações e conhecimentos sobre determinantes sociais da saúde no Brasil; contribuir para o desenvolvimento de políticas públicas e programas para a promoção da equidade em saúde; promover a mobilização de diferentes instâncias do governo e da sociedade civil sobre o tema ${ }^{67}$.

A abordagem conceitual que serviu de base para orientar as atividades e o conteúdo do relatório final da CNDSS foi o modelo de determinação social da saúde proposto por Whitehead e Dahlgren ${ }^{68}$, publicado também pela CNDSS ${ }^{69}$. A Figura 3 demonstra esse modelo.

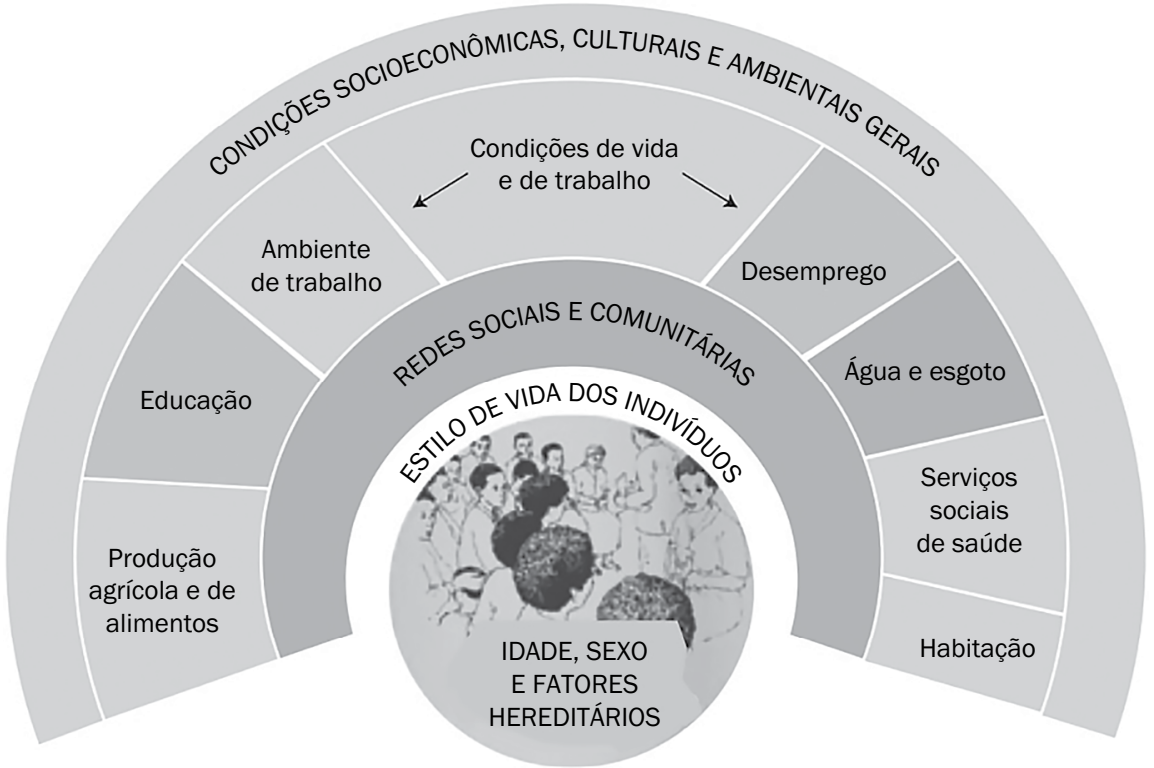

Fonte: Whitehead e Dahlgren, $2006^{70}$.

Figura 3. Determinantes Sociais da Saúde: modelo de Whitehead e Dahlgren

\footnotetext{
${ }^{66}$ BUSS, Paulo Marchiori; PELLEGRINI FILHO, Alberto. A saúde e seus determinantes sociais. Physis, Rio de Janeiro, v. 17, n. 1, p. 77-93, Apr. 2007. Disponivel em: http://www.scielo.br/scielo.php?script=sci_arttext\&pid=S0103$.73312007000100006 \&$ Ing=en\&nrm=iso. https://doi.org/10.1590/S0103-7331200700.

${ }^{67}$ Id. Ibid.

${ }^{68}$ WHITEHEAD, Margaret; DAHLGREN, Göran. Concepts and principles for tackling social inequities in health: Levelling up Part 1. WHO Collaborating Centre for Policy Research on Social Determinants of Health University of Liverpool. Copenhagen: World Health Organization, WHO, 2006. Disponível em: http://www. euro.who.int/_data/assets/pdf_file/0010/74737/E89383.pdf.

${ }^{69}$ WORLD HEALTH ORGANIZATION - WHO. Guidelines for drinking - water quality: recommendations, cit.

${ }^{70}$ WHITEHEAD, Margaret; DAHLGREN, Göran. op. cit.
} 
O modelo de Whitehead e Dahlgren apresenta os DSS em camadas, de acordo com seu nível de abrangência. Assim, há uma camada mais próxima aos determinantes individuais até outra mais periférica, onde se situam os macrodeterminantes, com correlação mais coletiva do que individual. Os indivíduos e suas características individuais (idade, sexo, carga genética) estão no centro do modelo (determinantes proximais à individualidade). Em seguida, em outra camada adjacente à primeira, estão os comportamentos e estilos de vida individuais. Na seguinte, encontram-se os fatores relacionados às condições de vida e laborais (determinantes intermediários) e a disponibilidade de alimentos e o acesso à educação e ao ambiente saudável, demonstrando que os indivíduos em desvantagem social estão mais suscetíveis aos riscos relacionados à saúde. Na camada mais periférica desse modelo, situam-se os considerados macrodeterminantes, que apresentam grande influência sobre as demais camadas e são relativos às condições socioeconômicas, culturais e ambientais da sociedade ${ }^{71,72}$.

Já o modelo de organização ou sistema de indicadores denominado Força Motriz-Pressão-Situação-Exposição-Efeito-Ações (FPSEEA) (Figura 4), elaborado pela OMS em conjunto com o Programa das Nações Unidas para o Meio Ambiente (Pnuma), contribui para o processo da análise dos DSS por meio de um conjunto de indicadores integrados. Esse modelo tem como objetivo abordar as inter-relações entre os fatores ambientais e a saúde. Trata-se de modelo adaptado de modelos ambientais pressão-estado-resposta (PER) e pressão-estado-impacto-resposta (PEIR) ${ }^{73}$.

A abordagem FPSEEA, adotada pela OMS e pela Organização Pan-Americana da Saúde (Opas), vem sendo utilizada pela Coordenação Geral de Vigilância em Saúde Ambiental (CGVAM) da Secretaria de Vigilância em Saúde (SVS) do Ministério da Saúde, com indicadores que permitem a análise integrada dos efeitos na saúde decorrentes da situação ambiental.

O modelo FPSEEA considera as atividades humanas como geradoras de "forças motrizes" que criam determinadas "pressões" sobre o meio ambiente, gerando "situações" que podem ser nocivas à saúde do ser humano. Essa nocividade ocorre por meio da "exposição ambiental", cujos “efeitos" impactam negativamente a expectativa de vida das pessoas, o que obriga os gestores públicos a tomar "ações" mitigadoras dos impactos observados.

Assim, enquanto o modelo de Whitehead e Dahlgren apresenta a fundamentação teórica para análise da situação de saúde de acordo com os determinantes socioambientais, o modelo FPSEEA permite a operacionalização dos indicadores de maneira integrada e sistêmica, por meio da organização em uma matriz que facilita a visualização e análise de possíveis inter-relações entre os diferentes indicadores ${ }^{74,75}$.

\footnotetext{
${ }^{71}$ BUSS, Paulo Marchiori; PELLEGRINI FILHO, Alberto. op. cit., p. 77-93.

${ }^{72}$ SOBRAL, André; FREITAS, Carlos Machado de. op. cit., p. 35-47.

${ }^{73}$ ORGANIZACIÓN PANAMERICANA DE LA SALUD - OPAS. Indicadores básicos de salud ambiental para La región de La frontera Mexico - Estados Unidos. Washington: Organización. Panamericana de la Salud, 2001.

${ }^{74}$ BUSS, Paulo Marchiori; PELLEGRINI FILHO, Alberto. op. cit., p. 77-93.

${ }^{75}$ SOBRAL, André; FREITAS, Carlos Machado de. op. cit., p. 35-47.
} 


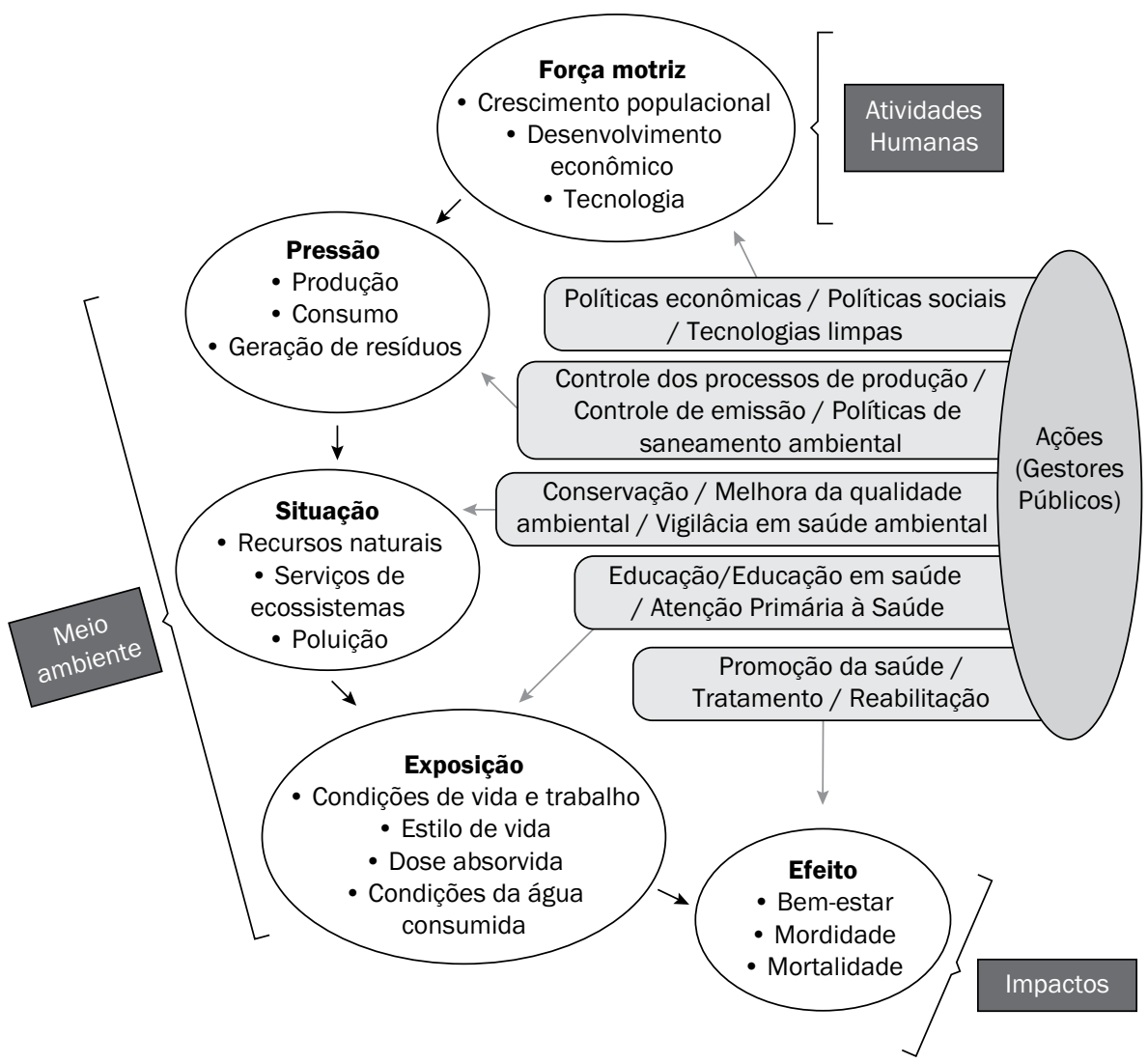

Fonte: Adaptado de OPAS, 2001.

Figura 4. Modelo de organização de indicadores Força Motriz-Pressão-Situação-Exposição-Efeito-Ações (FPSEEA)

\section{Eficiência dos tratamentos de água para potabilização na remoção de micropoluentes}

Uma crescente quantidade de publicações está disponível sobre a ocorrência de micropoluentes em água potável ${ }^{76}$. Os níveis mais altos de contaminantes emergentes nas águas podem ser explicados por suas elevadas persistências no ambiente.

No Brasil, a técnica mais completa e usual de tratamento de água para potabilização é a denominada "convencional". Nessa modalidade de tratamento,

${ }^{76}$ VULLIET, Emmanuelle; CREN-OLIVÉ, Cécile. Screening of pharmaceuticals and hormones at the regional scale, in surface and groundwaters intended to human consumption. Environmental Pollution, v. 159, n. 10, p. 2929-2934, May 2011. https://doi.org/10.1016/j.envpol.2011.04.033. 
a água bruta é coagulada, geralmente com um sal de alumínio ou de ferro, e, na sequência, floculada (coagulação-floculação). Esses métodos são eficientes, se bem conduzidos, na remoção dos sólidos que conferem turbidez e coloração à água. No entanto, essas técnicas convencionais têm se mostrado ineficientes para remoção de micropoluentes emergentes.

Pesquisa desenvolvida por Thuy et al. ${ }^{77}$ avaliou a remoção de quatro agrotóxicos (aldrin, dieldrin, atrazine, bentazone) por meio do processo de coagulação-floculação em água destilada e água do rio Dijle, na Bélgica. Os resultados desse estudo indicaram remoções inferiores a 50\%, para todos os compostos e em todas as condições avaliadas, e demonstraram que o aumento nas concentrações do coagulante apresentou efeito baixo ou insignificante na eficiência da remoção dos contaminantes. Ademais, os estudos apresentaram uma eficiência pior em experimentos conduzidos com água destilada, indicando que a remoção dos micropoluentes, nesses tratamentos, ocorre mais devido ao processo de sorção à matéria orgânica do que à desestabilização dos coloides, propiciada pela adição do coagulante.

Ormad et al. ${ }^{78}$ estudaram a eficiência de tratamentos de água para potabilização, comumente utilizados na Espanha. O estudo avaliou a remoção de 44 agrotóxicos comumente detectados na bacia do rio Ebro com diferentes técnicas de tratamento. Os autores mencionam que a técnica convencional consistiu no tratamento menos eficiente dentre os processos avaliados, sendo praticamente indiferente a dosagem de coagulante utilizada no tratamento.

A presença de agrotóxicos em águas potabilizáveis submetidas ao tratamento convencional também é apontada na pesquisa Stackelberg et al. ${ }^{79}$. Os resultados mostraram que a remoção média de orgânicos foi da ordem de $15 \%$ na clarificação, $32 \%$ na desinfecção e $53 \%$ na filtração em carvão ativado. Estudo publicado em 2003 pela Agência de Proteção Ambiental dos Estados Unidos $^{80}$ (United States Environmental Protection Agency - USEPA), sobre a eficiência de remoção de agrotóxicos em estações de tratamento de água para potabilização, já indicava baixa eficiência dos processos de coagulação com sulfato de alumínio.

\footnotetext{
${ }^{77}$ THUY, Pham Thi et al. op. cit., p. 217-223.

${ }^{78}$ ORMAD, Maria P.; MIGUEL, Natividad; CLAVER, Ana; MATESANZ, Jose M. Pesticides removal in the process of drinking water production. Chemosphere, v. 71, n. 1, p. 97-106, Apr. 2008. https://doi.org/10.1016/j. chemosphere.2007.10.006.

${ }^{79}$ STACKELBERG, Paul E.et al. op. cit., p. 255-272.

${ }^{80}$ UNITED STATES ENVIRONMENTAL PROTECTION AGENCY - USEPA. 2001 Toxics Release Inventory Executive Summary. U.S. Environmental Protection Agency Office of Environmental Information. Washington: USEPA, 2003.
} 
Saraiva Soares et al. ${ }^{81}$ estudaram a remoção de três agrotóxicos/metabólitos bastante utilizados em culturas de café de Minas Gerais - endosulfan e os metabólitos do mancozeb (ethylenethiourea, ETU) e do epoxiconazole (1,2,4-triazole). Os estudos também concluíram pela baixa eficiência de remoção desses micropoluentes. Os metabólitos ETU e 1,2,4-triazole obtiveram menores percentuais de remoção (ETU mediana $\leq 11 \%$ na água decantada, e 1,2,4-triazole $\leq 18 \%$ na água decantada) em relação ao endosulfan (mediana $\leq 54 \%$ na água decantada).

Para outros micropoluentes além dos agrotóxicos, a literatura técnica especializada também relata acerca da baixa eficiência de remoção obtida pelos métodos convencionais de tratamento para potabilização da água ${ }^{82,83}$.

Cabe informar que tecnologias de tratamento avançado, tais como ozonização, processos avançados de oxidação (POA), adsorção em carvão ativado, filtração, com membranas como microfiltração, ultrafiltração, nanofiltração e osmose reversa, são mais eficientes para remover micropoluentes. No entanto, tais técnicas de tratamento são mais onerosas, se comparadas ao método convencional de tratamento. Por isso, enfatiza-se a importância da adoção de medidas que contribuam para reduzir/mitigar a contaminação das águas. Dentre essas medidas, destaca-se a manutenção de áreas de preservação permanente nas bacias hidrográficas, onde há captação de água para abastecimento público, conforme preconizado no Código Florestal Brasileiro; adoção de "boas práticas" nessas bacias, como técnicas de manejo adequado de culturas agrícolas; evitar lançamento de esgotos nas águas, sem prévio tratamento; e implantação de bacias de acumulação de águas pluviais em áreas de lavouras ${ }^{84}$.

\section{Modelo Pressão-Estado-Resposta para o caso da contaminação das águas por micropoluentes}

Diante do cenário apresentado, a Figura 5 traz o modelo Pressão-Estado-Resposta para as situações debatidas, de forma a facilitar a compreensão pelo leitor, vez que permite análise integrada dos efeitos negativos decorrentes delas no ambiente e, por consequência, na saúde.

\footnotetext{
${ }^{82}$ RODRIGUEZ-MOZAZ, Sara; LÓPEZ DE ALDA, Maria J.; BARCELÓ, Damià. Monitoring of estrogens, pesticides and bisphenol $A$ in natural Waters and drinking water treatment plants by solid-phase extraction-liquid chromatography-mass spectrometry. Journal of Chromatography A, v. 1045, n 1-2, p. 85-92, Aug. 2004. https://doi.org/10.1016/j.chroma.2004.06.040.

${ }^{83} \mathrm{CHEN}$, C.Y. et al. Determining estrogenic steroids in Taipei waters and removal in drinking water treatment using high-flow solid-phase extraction and liquid chromatography/tandem mass spectrometry. Sci Total Environ, v. 378, n. 3, p. 352-365, Apr. 2007. https://doi.org/10.1016/j.scitotenv.2007.02.038.

${ }^{84}$ SOARES, Alexandra F. Saraiva; LEAO, M. M. D. Contaminação dos mananciais por micropoluentes e a precária remoção desses contaminantes nos tratamentos convencionais de água para potabilização. De Jure (Belo Horizonte), v. 14, p. 36-85, 2015.
} 


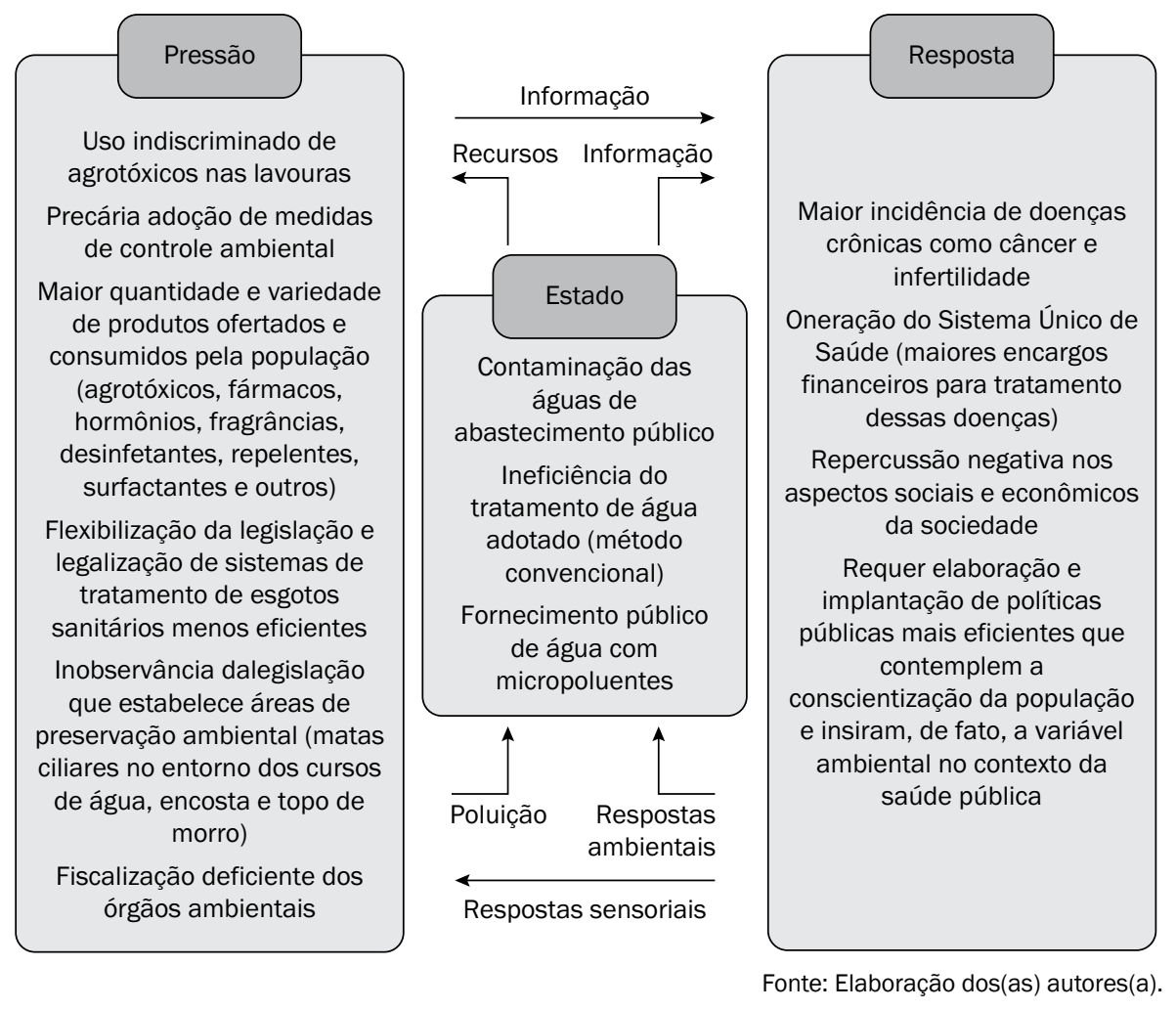

Figura 5. Modelo Pressão-Estado-Resposta para o cenário de contaminação das águas por micropoluentes elaborado pelos autores

\section{Análise da regulamentação existente para controle da contaminação das águas no âmbito do Direito Sanitário}

As características dos efeitos adversos dos micropoluentes se encaixam nos tipos de risco aos quais as sociedades modernas estão expostas.

As sociedades modernas, segundo Beck ${ }^{85}$, apresentam uma explosão de riscos cujos efeitos tendem cada vez mais a se evadir das instituições de controle e proteção da sociedade industrial. Os riscos conferidos pelos micropoluentes assumem as seguintes características: são ilimitados em função do tempo, globais no âmbito de seu alcance e potencialmente catastróficos. Assim, como

\footnotetext{
${ }^{85}$ BECK, Ulrich, U. A reinvenção da política: rumo a uma teoria de modernização reflexiva. In: BECK, Ulrich; GIDDENS, Anthony; LASH, Scott (Orgs.). Modernização reflexiva: política, tradição e estética na ordem social moderna. Trad. Magda Lopes. São Paulo: Universidade Estadual Paulista, 1997. p. 15.
} 
apresentado no item anterior, a produção e o consumo desenfreados de diversos produtos sintetizados (industrializados) têm resultado na contaminação dos mananciais de abastecimento público de água por micropoluentes, que, embora em concentrações iniciais baixas, têm efeitos acumulativos nos organismos dos seres vivos e potencialmente maléficos ao meio ambiente e à saúde humana.

Diante desse cenário, o Direito Sanitário possui um arcabouço legislativo importante no âmbito brasileiro e internacional. A legislação desse ramo das ciências jurídicas é bastante ampla, cujos principais atos normativos serão apresentados neste tópico.

O direito à saúde é reconhecido não só na Constituição da República Federativa do Brasil de $1988(\mathrm{CF} / 88)^{86}$, como também nos tratados e declarações de Direito Internacional. O tratado internacional que aborda a integração entre os ordenamentos jurídicos internacionais e nacionais é a Convenção de Viena sobre o Direito dos Tratados (1969), que estabelece que, uma vez integrado ao ordenamento pátrio, o tratado internacional possui força jurídica interna obrigatória e vinculante (art. $5^{\circ}, \S 3^{\circ}, \mathrm{CF} / 88$ ). Neste contexto, o Brasil encontra-se aberto ao fenômeno da internacionalização do direito, sobretudo no que tange à proteção dos direitos humanos, como o direito à saúde.

Há normas jurídicas criadas com o fim exclusivo de promover a proteção do direito à saúde, organizando as ações estatais para a prestação de serviços de saúde e estabelecendo infrações sanitárias e respectivas sanções. As leis brasileiras n. $5.991 / 1973^{87}$, n. $6.437 / 1977^{88}$, n. $8.080 / 1990^{89}$, n. $8.142 / 1990^{90}$ e n. $9.782 / 1999^{91}$ são exemplos dessas normas. Trata-se de fontes específicas do Direito Sanitário brasileiro. Há, também, normas jurídicas que possuem dispositivos de proteção do direito à saúde,

${ }^{86}$ BRASIL. Constituição da República Federativa do Brasil de 1988. Disponível em: http://www.planalto.gov. br/ccivil_03/constituicao/constituicaocompilado.htm. Acesso em: 18 fev. 2020.

${ }^{87}$ BRASIL. Lei n. 5.991, de 17 de dezembro de 1973. Dispõe sobre o controle sanitário do comércio de drogas, medicamentos, insumos farmacêuticos e correlatos, e dá outras providências. Disponível em: https://www.camara.leg.br/proposicoesWeb/prop_mostrarintegra;jsessionid=C929F7735341FFB852 FF6CA26C981F9D. proposicoesWeb2?codteor $=491873 \&$ filename=LegislacaoCitada $+-P L+1719 / 2007$. Acesso em: 18 fev. 2020.

${ }^{88}$ BRASIL. Lei n. 6.437, de 20 de agosto de 1977. Configura infrações à legislação sanitária federal, estabelece as sanções respectivas, e dá outras providências. Disponível em: http://www.planalto.gov.br/ ccivil_03/leis/16437.htm. Acesso em: 18 fev. 2020.

${ }^{89}$ BRASIL. Lei $n$. 8.080, de 19 de setembro de 1990. Dispõe sobre as condições para a promoção, proteção e recuperação da saúde, a organização e o funcionamento dos serviços correspondentes e dá outras providências. Disponível em: http://www.planalto.gov.br/ccivil_03/leis/L8080.htm. Acesso em: 18 fev. 2020.

${ }^{90}$ BRASIL. Lei n. 8.142, de 28 de dezembro de 1990. Dispõe sobre a participação da comunidade na gestão do Sistema Único de Saúde (SUS) e sobre as transferências intergovernamentais de recursos financeiros na área da saúde e dá outras providências. Disponível em: http://www.planalto.gov.br/ccivil_03/leis/ L8142.htm. Acesso em: 18 fev. 2020.

${ }^{91}$ BRASIL. Lei n. 9.782, de 26 de janeiro de 1999. Define o Sistema Nacional de Vigilância Sanitária, cria a Agência Nacional de Vigilância Sanitária, e dá outras providências. Disponível em: http://www.planalto.gov. br/ccivil_03/leis/19782.htm. Acesso em: 18 fev. 2020. 
mesmo não sendo editadas exclusivamente com esse propósito. Esses instrumentos normativos incluem: a CF/88, códigos Penal ${ }^{92}$, $\mathrm{Civil}^{93}$ e do Consumidor ${ }^{94}$, entre outras diversas normas que compõem a base do ordenamento jurídico nacional e possuem dispositivos de proteção do direito à saúde, constituindo fontes não específicas do Direito Sanitário brasileiro.

$\mathrm{Na}$ CF/88 estão destacadas, como fontes não específicas do Direito Sanitário, aquelas relacionadas a preservação ambiental (art. 225), educação, cultura e desporto (arts. 205 a 214), além de dispositivos esparsos que tratam de saneamento, infraestrutura urbana, habitação e direitos humanos fundamentais. No entanto, cabe salientar que a $\mathrm{CF} / 88$ apresenta também artigos destinados especificamente à tutela da saúde (art. $6^{\circ}$ e arts. 196 ao 200).

Para a concretização do denominado direito à saúde, são necessárias condições que assegurem a todos o acesso universal e igualitário às ações e aos serviços que objetivam promover, proteger e recuperar a saúde. Tanto o Estado quanto a iniciativa privada devem assumir essas ações e a prestação desses serviços de promoção da saúde na sociedade.

Na tentativa de facilitar a visualização, o Quadro 1 lista as principais legislações específicas e não específicas de Direito Sanitário nos contextos internacional e brasileiro.

Cabe salientar que o Direito Sanitário dispõe de regras e princípios próprios, sendo, portanto, ramo da ciência jurídica que disciplina as ações e os serviços públicos e privados de interesse à saúde.

As ações que visam à promoção da saúde podem ser de cunho preventivo (individual e coletivo, incluindo aqui as ações realizadas na implementação de serviços de saneamento: abastecimento de água potável de qualidade, coleta e destinação adequadas de esgotos sanitários e resíduos sólidos urbanos), ações de vigilância epidemiológica, ações de educação alimentar e de higiene, serviços de atendimento hospitalar e de urgência, serviços de diagnóstico, dentre outros ${ }^{95}$. 
Quadro 1. Relação da legislação específica e não específica de Direito Sanitário no contexto internacional e no brasileiro

\begin{tabular}{|c|c|c|c|c|}
\hline \multirow{3}{*}{ Contexto } & \multicolumn{4}{|c|}{ Legislação } \\
\hline & \multicolumn{2}{|c|}{$\begin{array}{l}\text { Específica de Direito } \\
\text { Sanitário }\end{array}$} & \multicolumn{2}{|l|}{ Não específica de Direito Sanitário } \\
\hline & Regra & Ano & Regra & Ano \\
\hline \multirow[t]{2}{*}{ Internacional } & \multirow{2}{*}{$\begin{array}{c}\text { Constituição } \\
\text { da Organização } \\
\text { Mundial da } \\
\text { Saúde }^{96}\end{array}$} & \multirow[t]{2}{*}{1946} & Carta das Nações Unidas $^{97}$ & 1945 \\
\hline & & & Declaração Universal dos Direitos Humanos ${ }^{98}$ & 1948 \\
\hline \multirow[t]{3}{*}{ Internacional } & \multirow{3}{*}{$\begin{array}{c}\text { Constituição } \\
\text { da Organização } \\
\text { Mundial da } \\
\text { Saúde }^{99}\end{array}$} & \multirow[t]{3}{*}{1946} & $\begin{array}{l}\text { Pacto Internacional sobre Direitos } \\
\text { Econômicos, Sociais e Culturais }{ }^{100}\end{array}$ & 1966 \\
\hline & & & Organização dos Estados Americanos ${ }^{101}$ & 1993 \\
\hline & & & $\begin{array}{c}\text { Convenção Americana sobre Direitos } \\
\text { Humanos }^{102}\end{array}$ & 1969 \\
\hline \multirow[t]{4}{*}{ Brasileiro } & \multirow[t]{2}{*}{ Lei n. 5.991} & \multirow[t]{2}{*}{1973} & Decreto n. 24.643 (Código das Águas) ${ }^{103}$ & 1934 \\
\hline & & & Decreto-Lei n. 2.848 & 1940 \\
\hline & \multirow[t]{2}{*}{ Lei n. $6.259^{104}$} & \multirow[t]{2}{*}{1975} & $\begin{array}{c}\text { Decreto-Lei n. } 4.657 \text { (Lei de Introdução ao } \\
\text { Código Civil) }\end{array}$ & 1942 \\
\hline & & & $\begin{array}{l}\text { Decreto-Lei n. } 5.452 \text { (Consolidação das Leis } \\
\text { do Trabalho - CLT) }{ }^{106}\end{array}$ & 1943 \\
\hline
\end{tabular}

${ }^{96}$ ORGANIZAÇÃO MUNDIAL DA SAÚDE - OMS. Constituição da Organização Mundial da Saúde (OMS/ WHO). Biblioteca Virtual de Direitos Humanos, Universidade de São Paulo. Disponível em: http://www. direitoshumanos.usp.br/index.php/OMS-Organiza\%C3\%A7\%C3\%A3o-Mundial-da-Sa\%C3\%BAde/ constituicao-da-organizacao-mundial-da-saude-omswho.html. Acesso em: 18 fev. 2020.

${ }^{97}$ A CARTA das Nações Unidas. Nações Unidas Brasil. Disponível em: https://nacoesunidas.org/carta/. Acesso em: 18 fev. 2020.

${ }^{98}$ A DECLARAÇÃO Universal dos Direitos Humanos. Nações Unidas Brasil. Disponível em: https:// nacoesunidas.org/direitoshumanos/declaracao/. Acesso em: 18 fev. 2020.

${ }^{99}$ ORGANIZAÇÃO MUNDIAL DA SAÚDE - OMS. Constituição da Organização Mundial da Saúde (OMS/ WHO). Biblioteca Virtual de Direitos Humanos, Universidade de São Paulo. Disponível em: http://www. direitoshumanos.usp.br/index.php/OMS-Organiza\%C3\%A7\%C3\%A3o-Mundial-da-Sa\%C3\%BAde/ constituicao-da-organizacao-mundial-da-saude-omswho.html. Acesso em: 18 fev. 2020.

${ }^{100}$ BRASIL. Decreto n. 591, de 6 de julho de 1992. Atos Internacionais. Pacto Internacional sobre Direitos Econômicos, Sociais e Culturais. Promulgação. Disponível em: http://www.planalto.gov.br/ccivil_03/ decreto/1990-1994/d0591.htm. Acesso em: 18 fev. 2020.

${ }^{101}$ ORGANIZAÇÃO DOS ESTADOS AMERICANOS - OAS. Departamento de Direito Internacional. Carta da Organização dos Estados Americanos. Disponível em: http://www.oas.org/dil/port/tratados_A-41_Carta_ da_Organiza\%C3\%A7\%C3\%A3o_dos_Estados_Americanos.htm. Acesso em: 18 fev. 2020.

${ }^{102}$ COMISSÃO INTERAMERICANA DEDIREITOS HUMANNOS - CIDH. Convenção Americana sobre Direitos Humanos. Disponível em: https://www.cidh.oas.org/basicos/portugues/c.convencao_americana.htm. Acesso em: 18 fev. 2020.

${ }^{103}$ BRASIL. Decreto n. 24.643, de 10 de julho de 1934. Decreta o Código de Águas. Disponível em: http:// www.planalto.gov.br/ccivil_03/decreto/D24643.htm. Acesso em: 18 fev. 2020.

${ }^{104}$ BRASIL. Lei n. 6.259 , de 30 de outubro de 1975. Dispõe sobre a organização das ações de Vigilância Epidemiológica, sobre o Programa Nacional de Imunizações, estabelece normas relativas à notificação compulsória de doenças, e dá outras providências. Disponível em: http://www.planalto.gov.br/ccivil_03/ leis/L6259.htm. Acesso em: 18 fev. 2020.

${ }^{105}$ BRASIL. Decreto-Lei n. 4.657, de 4 de setembro de 1942. Lei de Introdução às normas do Direito Brasileiro. (Redação dada pela Lei n. 12.376, de 2010). Disponível em: http://www.planalto.gov.br/ ccivil_03/decreto-lei/del4657.htm. Acesso em: 18 fev. 2020.

${ }^{106}$ BRASIL. Decreto-Lei n. 5.452, de $1^{\circ}$ de maio de 1943. Aprova a Consolidação das Leis do Trabalho. Disponivel em: http://www.planalto.gov.br/ccivil_03/decreto-lei/del5452.htm. Acesso em: 18 fev. 2020. 


\begin{tabular}{|c|c|c|c|c|}
\hline \multirow{3}{*}{ Contexto } & \multicolumn{4}{|c|}{ Legislação } \\
\hline & \multicolumn{2}{|c|}{$\begin{array}{c}\text { Específica de Direito } \\
\text { Sanitário }\end{array}$} & \multicolumn{2}{|l|}{ Não específica de Direito Sanitário } \\
\hline & Regra & Ano & Regra & Ano \\
\hline & \multirow[t]{2}{*}{ Lei n. $6.360^{107}$} & \multirow[t]{2}{*}{1976} & Lei 6.938 (Meio Ambiente) ${ }^{108}$ & 1981 \\
\hline & & & Lei n. 7.802 (Lei de agrotóxicos) $^{109}$ & 1989 \\
\hline \multirow[t]{8}{*}{ Brasileiro } & \multirow[t]{2}{*}{ Lei n. 6.437} & \multirow[t]{2}{*}{1977} & Lei n. 8.078 (Código do Consumidor) & 1990 \\
\hline & & & Lei n. 9.433 (Recursos hídricos) ${ }^{110}$ & 1997 \\
\hline & \multirow[t]{2}{*}{$\mathrm{CF} / 88$} & \multirow[t]{2}{*}{1988} & Lei n. 9.605 (Lei de crimes ambientais) ${ }^{111}$ & 1998 \\
\hline & & & Decreto n. $4.074^{112}$ & 2002 \\
\hline & \multirow{2}{*}{$\begin{array}{c}\text { Lei n. } 8.080 \text { (Lei } \\
\text { Orgânica da Saúde) }\end{array}$} & \multirow[t]{2}{*}{1990} & Lei n. 10.406 (Código Civil) & 2002 \\
\hline & & & 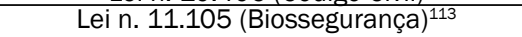 & 2005 \\
\hline & \multirow[t]{2}{*}{ Lei n. 8.142} & \multirow[t]{2}{*}{1990} & Lei n. 11.445 (Saneamento) $^{114}$ & 2007 \\
\hline & & & Lei n. 12.651 (Código Florestal Brasileiro) ${ }^{115}$ & 2012 \\
\hline
\end{tabular}

${ }^{107}$ BRASIL. Lei n. 6.360, de 23 de setembro de 1976. Dispõe sobre a Vigilância Sanitária a que ficam sujeitos os Medicamentos, as Drogas, os Insumos Farmacêuticos e Correlatos, Cosméticos, Saneantes e Outros Produtos, ae dá outras Providências. Disponível em: http://www.planalto.gov.br/ccivil_03/LEIS/L6360. htm. Acesso em: 18 fev. 2020.

${ }^{108}$ BRASIL. Lei n. 6.938, de 31 de agosto de 1981. Dispõe sobre a Política Nacional do Meio Ambiente, seus fins e mecanismos de formulação e aplicação, e dá outras providências. Disponível em: http://www. planalto.gov.br/ccivil_03/LEIS/L6938.htm. Acesso em: 18 fev. 2020.

${ }^{109}$ BRASIL. Lei n. 7.802, de 11 de julho de 1989.Dispõe sobre a pesquisa, a experimentação, a produção, a embalagem e rotulagem, o transporte, o armazenamento, a comercialização, a propaganda comercial, a utilização, a importação, a exportação, o destino final dos resíduos e embalagens, o registro, a classificação, o controle, a inspeção e a fiscalização de agrotóxicos, seus componentes e afins, e dá outras providências. Disponivel em: http://www.planalto.gov.br/ccivil_03/LEIS/L7802.htm. Acesso em: 18 fev. 2020.

${ }^{110}$ BRASIL. Lei n. 9.433, de 8 de janeiro de 1997. Institui a Política Nacional de Recursos Hídricos, cria o Sistema Nacional de Gerenciamento de Recursos Hídricos, regulamenta o inciso XIX do art. 21 da Constituição Federal, e altera o art. $1^{\circ}$ da Lei n. 8.001, de 13 de março de 1990, que modificou a Lei n. 7.990, de 28 de dezembro de 1989. Disponível em: http://www.planalto.gov.br/ccivil_03/LEIS/L9433.htm. Acesso em: 18 fev. 2020.

${ }^{111}$ BRASIL. Lei $n$. 9.605, de 12 de fevereiro de 1998. Dispõe sobre as sanções penais e administrativas derivadas de condutas e atividades lesivas ao meio ambiente, e dá outras providências. Disponível em: http://www.planalto.gov.br/ccivil_03/leis/19605.htm. Acesso em: 18 fev. 2020.

${ }^{112}$ BRASIL. Decreto n. 4.074, de 4 de janeiro de 2002. Regulamenta a Lei n. 7.802, de 11 de julho de 1989, que dispõe sobre a pesquisa, a experimentação, a produção, a embalagem e rotulagem, o transporte, 0 armazenamento, a comercialização, a propaganda comercial, a utilização, a importação, a exportação, o destino final dos resíduos e embalagens, o registro, a classificação, o controle, a inspeção e a fiscalização de agrotóxicos, seus componentes e afins, e dá outras providências. Disponível em: http://www.planalto. gov.br/ccivil_03/decreto/2002/d4074.htm. Acesso em: 18 fev. 2020.

${ }^{113}$ BRASIL. Lei $n$. 11.105, de 24 de março de 2005. Regulamenta os incisos II, IV e V do $\S 1^{\circ}$ do art. 225 da Constituição Federal, estabelece normas de segurança e mecanismos de fiscalização de atividades que envolvam organismos geneticamente modificados - OGM e seus derivados, cria o Conselho Nacional de Biossegurança - CNBS, reestrutura a Comissão Técnica Nacional de Biossegurança - CTNBio, dispõe sobre a Política Nacional de Biossegurança - PNB, revoga a Lei n. 8.974, de 5 de janeiro de 1995, e a Medida Provisória n. 2.191-9, de 23 de agosto de 2001 , e os arts. $5^{\circ}, 6^{\circ}, 7^{\circ}, 8^{\circ}, 9^{\circ}, 10$ e 16 da Lei $n$. 10.814, de 15 de dezembro de 2003, e dá outras providências. Disponível em: http://www.planalto.gov. br/ccivil_03/_Ato2004-2006/2005/Lei/L11105.htm. Acesso em: 18 fev. 2020.

${ }^{114}$ BRASIL. Lei n. 11.445, de 5 de janeiro de 2007. Estabelece diretrizes nacionais para o saneamento básico; altera as Leis ns. 6.766, de 19 de dezembro de 1979, 8.036, de 11 de maio de 1990, 8.666, de 21 de junho de 1993, 8.987, de 13 de fevereiro de 1995; revoga a Lei no 6.528, de 11 de maio de 1978; e dá outras providências. Disponível em: http://www.planalto.gov.br/ccivil_03/_ato2007-2010/2007/lei/l11445.htm. Acesso em: 18 fev. 2020.

${ }^{115}$ BRASIL. Lei n. 12.651, de 25 de maio de 2012. Dispõe sobre a proteção da vegetação nativa; altera as Leis ns. 6.938, de 31 de agosto de 1981, 9.393, de 19 de dezembro de 1996, e 11.428, de 22 de dezembro de 2006; revoga as Leis ns. 4.771, de 15 de setembro de 1965, e 7.754, de 14 de abril de 1989, e a Medida Provisória n. 2.166-67, de 24 de agosto de 2001; e dá outras providências. Disponível em: http://www. planalto.gov.br/ccivil_03/_ato2011-2014/2012/lei/I12651.htm. Acesso em: 18 fev. 2020. 
Dessa forma, o Direito Sanitário orienta e vincula interpretações e decisões relacionadas ao tema em tela (saúde). O conjunto de normas pertinentes à questão é sistematizado à luz da CF/88 e dos princípios jurídicos, tais como: legalidade, separação dos poderes, desenvolvimento sustentável, prevenção, precaução, não retrocesso, dentre outros. No entanto, as nuances da complexa sociedade atual também devem ser sempre consideradas para apoiar as interpretações das normas e as decisões finais. Diante disso, o Direito Sanitário deve ser entendido como um ramo jurídico autônomo, dotado de regras e princípios próprios, harmônicos entre si, com legitimidade jurídica e social.

O conjunto sistematizado e harmônico de normas jurídicas do Direito Sanitário deverá dispor de unidade lógica, sistêmica e funcional:

(i) unidade lógica: justifica-se pelo fato de suas normas estarem subordinadas a um conjunto uniforme de princípios jurídico-normativos que estão definidos constitucionalmente e aprofundados por leis ordinárias, decretos e regulamentos. Os princípios garantem a unicidade e a coerência desse ramo da ciência jurídica, vez que guiam (norteiam) a produção e aplicação das normas. Nenhuma norma jurídica deverá contrariar um princípio pré-estabelecido;

(ii) unidade sistêmica: justifica-se pelo fato de o conjunto normativo possuir estrutura, instituições, mecanismos e operações específicos. Dessa forma, há normas jurídicas do Direito Sanitário que definem a maneira como o direito se relaciona com a sociedade no que tange às ações e aos serviços de promoção, proteção e recuperação da saúde. O SUS, instituído pela $\mathrm{CF} / 88$, é um exemplo disso, vez que é fonte de produção normativa do Direito Sanitário, com especificidades não encontradas em nenhuma outra área do direito, e constitui instituição específica do Direito Sanitário, com mecanismos próprios, tais como Conselhos e Conferências de Saúde; e

(iii) unidade funcional: já que são normas jurídicas que estabelecem condutas, obrigações, comportamentos e comandos relacionados com a promoção, proteção e recuperação da saúde. Ademais, outra característica funcional do Direito Sanitário diz respeito à produção de suas normas jurídicas, que são reguladas e previstas no âmbito do conjunto normativo que compõe esse ramo da ciência jurídica. Esse conjunto de normas caracteriza-se pela regulação e pelo direcionamento da sociedade para a efetivação do direito à saúde pela população ${ }^{116}$.

Sabe-se que a norma jurídica consiste no elemento nuclear do Direito Sanitário, sendo assim sua fonte direta. As normas ordenam as relações sociais e impõem comportamentos que são assegurados pela autoridade pública. As normas constituem um dever ser, um imperativo, e traduzem atos de vontade que regem comportamentos de pessoas inseridas em uma sociedade. Essa modalidade de normas

\footnotetext{
${ }^{116}$ AITH, Fernando Mussa Abujamra. op. cit.
} 
- intituladas jurídicas - difere daquelas denominadas morais, éticas e sociais, por exemplo, porque é atrelada a sanções por seu descumprimento.

Assim, entende-se que as normas jurídicas são regras gerais, abstratas e vinculantes, orientadas para uma concretização material, como bem ensina Canotilho $^{117}$. No entanto, a norma jurídica, para ser válida, deve atender a procedimentos próprios que determinam sua forma de criação (ritos próprios de cada modalidade de norma) e procedimentos pré-estabelecidos para sua elaboração e, ainda, ser editada por órgãos específicos.

A norma jurídica traz consigo dois elementos essenciais, que são o mandamento e a sanção. Dessa maneira, a norma prescreve ou proíbe determinados tipos de comportamentos, cria obrigações - fazer (normas positivas) ou deixar de fazer (normas negativas) algo -, legitima atitudes, atribui poderes especiais etc. No que tangem ao Direito Sanitário, os mandamentos relacionam-se às ações e aos serviços públicos e privados vinculados ao tema da saúde. São exemplos de normas positivas: o próprio direito à saúde, referenciado nos artigos 6 e 196 da CF/88; o direito conferido ao portador de HIV de receber coquetel de medicamentos; a autorização para certos atos específicos, como vacinação de crianças e comercialização de alimentos, dentre outros. Já as ordens negativas incluem as proibições, por exemplo, de comercializar medicamentos sem registro (tipificados nos arts. 267 a 285 do Código Penal Brasileiro, que tratam dos crimes contra a saúde pública).

A sanção representa a consequência pelo descumprimento da conduta imposta pela norma jurídica e, geralmente, relaciona-se com a ideia de coerção. As sanções podem ter formas e intensidades variáveis e exigir reparação de prejuízo causado a outrem ou indenização, por exemplo.

A norma geral, abstrata e impessoal aplica-se a todos que preenchem seus requisitos e tem vigência desde sua entrada em vigor até sua ab-rogação, garantindo-lhe imparcialidade - pressuposto relevante no Estado de Direito -, vez que protege os cidadãos contra eventuais arbitrariedades.

O Direito Sanitário fundamenta-se em normas jurídicas constitucionais estabelecidas pela CF/88, consolida-se por meio de normas ordinárias federais que organizam o Sistema Único de Saúde (SUS), criam autarquias de saúde (Agência Nacional de Vigilância Sanitária, Agência Nacional de Saúde Complementar etc.) e estabelecem infrações sanitárias, dentre outras.

Se o Estado não cumpre seu dever de garantir o acesso aos serviços básicos - como distribuir água de qualidade - e alguém sofre um dano em decorrência dessa omissão estatal, tal dano será indenizado pelo Estado, independentemente de

${ }^{117}$ CANOTILHO, José Joaquim Gomes. Direito constitucional e teoria geral da Constituição. 7. ed. Coimbra: Almedina, 2012. 
se comprovar a culpa do agente responsável, vez que se trata de responsabilidade civil objetiva ${ }^{118}$. Ressalta-se que, em regra, as responsabilidades diversas podem ser aplicadas de forma autônoma ou cumulativa. Assim, um mesmo ato pode ensejar as responsabilidades civil, administrativa e penal, simultaneamente.

\section{Considerações finais}

Compreender as relações entre os determinantes socioambientais e a degradação da qualidade da água - por meio de indicadores - é de grande relevância para intervir na melhoria das condições de vida e de saúde das populações em vulnerabilidade. Nesse contexto, o Estado deve atuar regulando comportamentos e impondo regras de conduta de forma a preservar a qualidade ambiental e promover a saúde pública. As políticas públicas de saúde e ambientais devem estar em sintonia para que sejam efetivas no alcance de seus objetivos.

Diante dos riscos potenciais existentes e associados à poluição da água, este trabalho apresentou os principais dispositivos jurídicos existentes para tutelar a qualidade da água de abastecimento público no âmbito do Direito Sanitário. Constata-se que o arcabouço normativo para garantir o direito à água com abastecimento de qualidade é vasto e deve ser mais bem considerado pelo poder público e pela coletividade, de forma a promover saúde à população.

Os agentes públicos e a sociedade devem compreender que, ao se preservar a qualidade dos mananciais de abastecimento de água, estarão, consequentemente, promovendo saúde pública e desonerando o sistema de saúde. Para tanto, faz-se imprescindível a disseminação de informações acerca dos riscos potenciais da poluição da água associados com a perda da qualidade de vida, e a compreensão pelas autoridades competentes dos riscos de se autorizar/realizar captação de água, para fins de abastecimento público, em mananciais receptores de esgotos e, portanto, contaminados com micropoluentes, como a grande obra que está em implantação no município de Brumadinho para retirar cinco mil litros por segundo de água do rio Paraopeba, historicamente poluído por esgotos domésticos, efluentes industriais, dentre outros, e cujas águas serão submetidas, antes da distribuição para a região metropolitana de Belo Horizonte, ao tratamento convencional que constitui técnica não adequada para remover micropoluentes.

O poder público (além dos particulares) certo de que determinada atividade implicará dano futuro, deveria evitá-la. O Estado Democrático tem o dever de agir preventivamente, deve ser o guardião, por excelência, das expectativas legítimas das presentes e futuras gerações, embora, não raro, o aparato governamental trabalha

\footnotetext{
${ }^{118}$ MINISTÉRIO DA SAÚDE - MS. Secretaria de Vigilância em Saúde. Manual de direito sanitário com enfoque na vigilância em saúde. Ministério da Saúde, Secretaria de Vigilância em Saúde. Brasília-DF: Ministério da Saúde, 2006.
} 
contra tal lógica, preso a demandas imediatistas e incapazes de solucionar, de fato, os problemas da sociedade. Por mais relevantes e justas que se mostrem as reivindicações do tempo imediato, o Estado existe, sobretudo, para assegurar as regras impostas pela Constituição contra os humores voláteis e as irresponsabilidades para com o futuro e as demais causas geradoras de conflitos intertemporais. Deve-se, portanto, superar os desafios e imprimir eficácia aos princípios jurídicos da prevenção, precaução, do não retrocesso, dentre outros, em todas as relações da administração, não apenas no campo ambiental e sanitário, mas na denominada gestão de riscos.

Traços de poluentes emergentes em água potável têm se tornado uma crescente causa de preocupação para governos e autoridades em países desenvolvidos, devido a seus malefícios potenciais (possibilidade em causar doenças crônicas como câncer e infertilidade humana). Portanto, a mitigação da contaminação dos mananciais torna-se imperiosa em todos os países, visando a reduzir risco potencial à saúde humana relacionado ao consumo da água.

Água considerada potável pode conter micropoluentes que não estão regulamentados pela norma de potabilidade. Com a evolução da química analítica, essas informações estarão cada vez mais claras, propiciando a revisão da legislação pertinente de forma a oferecer maior controle dessa contaminação. Enquanto isso, situações como uso indiscriminado de agrotóxicos, flexibilização da legislação que estabelece os padrões para lançamento de esgoto nos recursos hídricos, captação de água em mananciais contaminados por esgoto (como no rio Paraopeba e rio das Velhas), dentre outros fatores constatados no cenário de Minas Gerais e de outros estados brasileiros, que conferem risco à saúde da população, devem ser evitadas, de acordo com as normas (regras e princípios- princípios da prevenção/precaução, proibição do retrocesso e responsabilidade, por exemplo) do Direito à Saúde.

As iniquidades em saúde atingem todos os países e são influenciadas pela política e economia vigentes. A ocorrência dos agravos em saúde relaciona-se com as condições em que as pessoas nascem, vivem e trabalham, apresentando direta correlação com as condições sociais e ambientais, além de fatores econômicos e culturais. Fortalecer a equidade em saúde significa ir além das intervenções concentradas exclusivamente sobre as causas imediatas das doenças. Assim, a atuação preventiva do poder público (Estado), definindo e adotando regras de condutas, e da sociedade civil, monitorando o cumprimento das regras estabelecidas, faz-se imprescindível na conservação do meio ambiente e na proteção da saúde da população, garantindo o direito à água de qualidade, que se constitui como um direito fundamental.

\section{Referências}

AITH, Fernando Mussa Abujamra. Curso de direito sanitário: a proteção do direito à saúde no Brasil. São Paulo: Quartier Latin, 2007. 
ALVES, T. C.; GIRARDI, R.; PINHEIRO, A. Micropoluentes orgânicos: ocorrência, remoção e regulamentação. Revista de Gestão de Água da América Latina, v. 14, e1, 2017. 10.21168/rega.v14n0.p0-1.

BARATA, Rita Barradas. Desigualdades sociais e saúde. In: CAMPOS, Gastão Wagner de Sousa. et al. Tratado de saúde coletiva. Rio de Janeiro: Hucitec; Editora Fiocruz, 2006. p. 457-486.

BECK, Ulrich, U. A reinvenção da política: rumo a uma teoria de modernização reflexiva. In: BECK, Ulrich; GIDDENS, Anthony; LASH, Scott (Orgs.). Modernização reflexiva: política, tradição e estética na ordem social moderna. Trad. Magda Lopes. São Paulo: Universidade Estadual Paulista, 1997.

BILGEHAN, Nas; TAYLAN, Dolu; HAVVA, Ates; ARGUN, M. Emim; YEL, Esra. Treatment alternatives for micropollutant removal in wastewater. University Selcuk Journal of Engineering, Science and Technology, v. 5, n. 2, p. 133-143, feb. 2017. Disponível em: https://www.researchgate. net/publication/319612877_TREATMENT_ALTERNATIVES_FOR_MICROPOLLUTANT_ REMOVAL_IN_WASTEWATER. https://doi.org/10.15317/Scitech.2017.77.

BUSS, Paulo Marchiori; PELLEGRINI FILHO, Alberto. A saúde e seus determinantes sociais. Physis, Rio de Janeiro, v. 17, n. 1, p. 77-93, Apr. 2007. Disponível em: http://www.scielo.br/ scielo.php?script=sci_arttext\&pid=S0103-.73312007000100006\&lng=en\&nrm=iso. https:// doi.org/10.1590/S0103-7331200700.

CAMACHO-MUÑOZ, Dolores; MARTIN, Jarolímek; SANTOS, J. L.; ALONSO, E. Effectiveness of conventional and low-cost wastewater treatments in the removal of pharmaceutically active compounds. Water, Air, \& Soil Pollution, v. 223, n. 5, p. 2611-2621, Jun. 2012. https://doi.org/10.1007/s11270-011-1053-9.

CANOTILHO, José Joaquim Gomes. Direito constitucional e teoria geral da Constituição. 7. ed. Coimbra: Almedina, 2012.

CHEN, C.Y. et al. Determining estrogenic steroids in Taipei waters and removal in drinking water treatment using high-flow solid-phase extraction and liquid chromatography/ tandem mass spectrometry. Sci Total Environ, v. 378, n. 3, p. 352-365, Apr. 2007. https://doi.org/10.1016/j.scitotenv.2007.02.038.

CLARA, M. et al. Identification of relevant micropollutants in Austrian municipal wastewater and their behaviour during wastewater treatment. Chemosphere, v. 87, n. 11, p.1265-1272, June 2012. https://doi.org/10.1016/j.chemosphere.2012.01.033.

DESCHAMPS, E. et al. Management of effluents and waste from pharmaceutical industry in Minas Gerais, Brazil. Braz. J. Pharm. Sci., São Paulo, v. 48, n. 4, p. 727-736, Oct./Dec. 2012. Disponível em: http://www.scielo.br/pdf/bjps/v48n4/v48n4a17.pdf. https://doi.org/10.1590/ S1984-82502012000400017.

FERREIRA, Maria Leonor Paes Cavalcanti. A pulverização aérea de agrotóxicos no Brasil: cenário atual e desafios. Revista de Direito Sanitário, São Paulo, v. 15, n. 3, p. 18-45, 14 abr. 2015. Disponível em: http://www.revistas.usp.br/rdisan/article/view/97324/96336. https:// doi.org/10.11606/issn.2316-9044.v15i3p18-45. 
GHISELLI, Gislaine; JARDIM, Wilson F. Interferentes endócrinos no ambiente. Química Nova, São Paulo, v. 30, n. 3, p. 695-706, jun. 2007. Disponível em: http://www.scielo.br/pdf/ qn/v30n3/31.pdf. https://doi.org/10.1590/S0100-40422007000300032.

GREGOR, D. J.; GUMMER, W. D. Evidence of atmospheric transport and deposition of organochlorine pesticides and polychlorinated biphenyls in Canadian artic snow. Environ. Sci. Technol., v. 23, n. 5, p. 561-565, May 1989. https://doi.org/10.1021/es00063a008.

HALLING-SORENSEN, B. et al. Occurrence, fate and effects of pharmaceutical substances in the environment - A review. Chemosphere, v.36, n. 2, p. 357-393, Jan. 1998. https://doi. org/10.1016/S0045-6535(97)00354-8.

HANSEN, Julie Hjerl. Brazilian coffee is sprayed with deadly pesticides. Danwatch, 10 Mar. 2016. Disponível em: https://old.danwatch.dk/en/nyhed/brasiliansk-kaffe-sproejtes-medlivsfarlige-pesticider/. Acesso em: 25 dez. 2018.

INSTITUTO BRASILEIRO DE GEOGRAFIA E ESTATÍSTICA - IBGE. Uso de Agrotóxicos - 1 Consumo nacional de agrotóxicos e afins por área plantada. Período: 2000-2014. (Séries históricas e estatísticas). Disponível em: https://seriesestatisticas.ibge.gov.br/series. aspx? vcodigo=IU18\&t=uso-agrotoxicos-1-consumo-nacional-agrotoxicos. Acesso em: 25 dez. 2018.

KASPRZYK-HORDERN, B.; DINSDALE, R.M.; GUWY, A.J. The removal of pharmaceuticals, personal care products, endocrine disruptors and illicit drugs during wastewater treatment and its impact on the quality of receiving waters. Water Res., v. 43, n. 2, p. 363-380, Feb. 2009. https://doi.org/10.1016/j.watres.2008.10.047.

KÖCK-SCHULMEYER, Marianne et al. Occurrence and behavior of pesticides in wastewater treatment plants and their environmental impact. Science of The Total Environment, v. 458460, p. 466-476, Aug. 2013. https://doi.org/10.1016/j.scitotenv.2013.04.010.

KRISTENSEN, David Møbjerg et al. Intrauterine exposure to mild analgesics is a risk factor for development of male reproductive disorders in human and rat. Human Reproduction, v. 26, n. 1, p. 235-244, Jan. 2011. https://doi.org/10.1093/humrep/deq323.

LONDRES, Flavia. Agrotóxicos no Brasil: um guia para ação em defesa da vida. Rio de Janeiro: Assessoria e Serviços a Projetos em Agricultura Alternativa, 2011.

LUO, Yun long et al. A review on the occurrence of micropollutants in the aquatic environment and their fate and removal during wastewater treatment. Science of the Total Environment, v. 473-474, p. 619-641, Mar. 2014. https://doi.org/10.1016/j.scitotenv.2013.12.065.

MARMOT, Michael. Health in an unequal world. The Lancet, v. 368, n. 9552, p. 2081-2094, Dec. 2006.

MINISTÉRIO DA AGRICULTURA, PECUÁRIA E ABASTECIMENTO - MAPA. Agrotóxicos, 2017. Disponível em: http://www.agricultura.gov.br/assuntos/insumos-agropecuarios/ insumos-agricolas/agrotoxicos. Acesso em: 22 out. 2017. 
MINISTÉRIO DA SAÚDE - MS. Secretaria de Vigilância em Saúde. Manual de direito sanitário com enfoque na vigilância em saúde. Brasília, DF: Ministério da Saúde, 2006.

MOTTA, Débora. Portal reúne dados sobre agrotóxicos no País. Fundação de Amparo à Pesquisa do Estado do Rio de Janeiro-FAPERJ, 25 ago. 2016. Disponível em: http://www.faperj. $\mathrm{br} /$ ?id=3222.2.2. Acesso em: $25 \mathrm{dez} .2018$.

ORGANIZAÇÃO MUNDIAL DA SAÚDE - OMS. Constituição da Organização Mundial da Saúde (OMS/WHO). Biblioteca Virtual de Direitos Humanos, Universidade de São Paulo. Disponível em: http://www.direitoshumanos.usp.br/index.php/OMSOrganiza\%C3\%A7\%C3\%A3o-Mundial-da-Sa\%C3\%BAde/constituicao-da-organizacaomundial-da-saude-omswho.html. Acesso em: 18 fev. 2020.

ORGANIZACIÓN PANAMERICANA DE LA SALUD - OPAS. Indicadores básicos de salud ambiental para La región de La frontera Mexico - Estados Unidos. Washington: Organización Panamericana de la Salud, 2001.

ORMAD, Maria P.; MIGUEL, Natividad; CLAVER, Ana; MATESANZ, Jose M. Pesticides removal in the process of drinking water production. Chemosphere, v. 71, n. 1, p. 97-106, Apr. 2008. https://doi.org/10.1016/j.chemosphere.2007.10.006.

RODRIGUEZ-MOZAZ, Sara; LÓPEZ DE ALDA, Maria J.; BARCELÓ, Damià. Monitoring of estrogens, pesticides and bisphenol $A$ in natural Waters and drinking water treatment plants by solid-phase extraction-liquid chromatography-mass spectrometry. Journal of Chromatography A, v. 1045, n 1-2, p. 85-92, Aug. 2004. https://doi.org/10.1016/j.chroma.2004.06.040.

SANTOS, Cristina Mamédio da Costa; PIMENTA, Cibele Andrucioli de Mattos; NOBRE, Moacyr Roberto Cuce. A estratégia PICO para a construção da pergunta de pesquisa e busca de evidências. Rev. Latino-Am. Enfermagem, Ribeirão Preto, v. 15, n. 3, p. 508-511, jun. 2007. Disponível em: http:// www.scielo.br/pdf/rlae/v15n3/pt_v15n3a23.pdf.https://doi.org/10.1590/S0104-11692007000300023.

SCHAIDER, L. et al. Emerging contaminants in Cape Cod private drinking water wells. Reserching the environment and women's health. Silent Spring Institute, 2011. Disponível em: http://www.silentspring. org/sites/default/files/Emerging-contaminants-private-wells.pdf. Acesso em: 21 mar. 2014.

SCHOMBURG, C.J.; GLOTFLELTY, D.E. Pesticide occurrence and distribution in fog collected near Monterey, California. Environ. Sci. Technol., v. 25, n. 1, p. 155-160, Jan. 1991. https://doi.org/10.1021/es00013a018.

SILVA, Larissa L.; MOREIRA, Carolina G.; CURZIO, Bianca A.; FONSECA, Fabiana V. Micropollutant removal from water by membrane and advanced oxidation processes: a review. Journal of Water Resource and Protection, v. 9, n. 5, p. 411-431, abr. 2017. Disponível em: https://www.scirp.org/pdf/JWARP_2017041715102681.pdf. https://doi.org/10.4236/ jwarp.2017.95027.

SISTEMAS DE AGROTÓXICOS FITOSSANITÁRIOS - AGROFIT. Consulta de Produtos Formulados. Disponível em: http://agrofit.agricultura.gov.br/agrofit_cons/principal_agrofit_ cons. Acesso em: 25 dez. 2018. 
SOARES, Alexandra F. Saraiva et al. Efficiency of conventional drinking water treatment process in the removal of endosulfan, ethylenethiourea, and 1,2,4-triazole. Journal of Water Supply: Research and Technology-AQUA, v. 62, n. 6, p. 367-376, Sept. 2013. https://doi.org/10.2166/aqua.2013.042.

SOARES, Alexandra F. Saraiva et al. Risk estimate of water contamination by pesticides used in coffee crops. Rev. bras. eng. agríc. ambient., Campina Grande, v. 16, n. 4, p. 425-432, abr. 2012. Disponível em: http://www.scielo.br/pdf/rbeaa/v16n4/v16n04a13.pdf. https://doi. org/10.1590/S1415-43662012000400013.

SOARES, Alexandra F. Saraiva. Impacto do uso de agrotóxicos na qualidade da água: estudo de caso em região produtora de café. 1. ed. Novas Edições Acadêmicas, 2015.

SOARES, Alexandra F. Saraiva. Pesticides environmental destination: a study based on coffee productive areas Belo Horizonte: Editor: Tiago Silveira Gontijo, 2018. 91 p.

SOARES, Alexandra F. Saraiva; LEAO, M. M. D. Contaminação dos mananciais por micropoluentes e a precária remoção desses contaminantes nos tratamentos convencionais de água para potabilização. De Jure (Belo Horizonte), v. 14, p. 36-85, 2015.

SOARES, Alexandra F. Saraiva; MACHADO, A.O.V.; DINIZ, P.S. Informações técnicas referentes à Deliberação Normativa Conjunta COPAM/CERH-MG No 1, de 5 de maio de 2008. Parecer Técnico. ID SGDP 1011391. 2008. Disponível em: https://intranet.mpmg.mp.br/intranetmpmg/ institucional/central-de-apoio-tecnico/meio-ambiente/. Acesso em: 23 out. 2017.

SOBRAL, André; FREITAS, Carlos Machado de. Modelo de organização de indicadores para operacionalização dos determinantes socioambientais da saúde. Saude soc., v. 19, n. 1, p. 35-47, mar. 2010. Disponível em: http://www.scielo.br/pdf/sausoc/v19n1/04.pdf. https:// doi.org/10.1590/S0104-12902010000100004.

SOLAR, O.; IRWIN, A. Towards a conceptual framework for analysis and action on the social determinants of health. Geneva: WHO Commission on Social Determinants of Health, 2007. (Discussion Paper Series on Social Determinants of Health, 2).

STACKELBERG, Paul E.et al. Efficiency of conventional drinking-water-treatment processes in removal of pharmaceuticals and other organic compounds. Science of the Total Environment, v. 377, n. 2-3, p. 255-272, May 2007. https://doi.org/10.1016/j.scitotenv.2007.01.095.

THUY, Pham Thi et al. To what extent are pesticides removed from surface water during coagulation- flocculation? Water and Environment Journal, v. 22, n. 3, p. 217-223, jul. 2008. https://doi.org/10.1111/j.1747-6593.2008.00128.x.

UNITED STATES ENVIRONMENTAL PROTECTION AGENCY - USEPA. 2001 Toxics Release Inventory Executive Summary. U.S. Environmental Protection Agency Office of Environmental Information. Washington: USEPA, 2003.

VULLIET, Emmanuelle; CREN-OLIVÉ, Cécile. Screening of pharmaceuticals and hormones at the regional scale, in surface and groundwaters intended to human consumption. Environmental Pollution, v. 159, n. 10, p. 2929-2934, May 2011. https://doi.org/10.1016/j.envpol.2011.04.033. 
WHITEHEAD, Margaret; DAHLGREN, Göran. Concepts and principles for tackling social inequities in health: Levelling up Part 1. WHO Collaborating Centre for Policy Research on Social Determinants of Health University of Liverpool. Copenhagen: World Health Organization, WHO, 2006. Disponível em: http://www.euro.who.int/_data/assets/pdf_ file/0010/74737/E89383.pdf.

WORLD HEALTH ORGANIZATION - WHO. Guidelines for drinking - water quality: recommendations. Second Addendum to Third Edition. Geneva: WHO, 2008. v. 1. Disponível em: http://www.who.int/water_sanitation_health/dwq/fulltext.pdf. Acesso em: 22 out. 2017.

ZHANG, Y.; GEISSEN, Sven-Uwe; GAL, Carmen. Carbamazepine and diclofenac: removal in wastewater treatment plants and occurrence in water bodies. Chemosphere, v. 73, n. 8, p. 1151-1161, Nov. 2008. 32923874

Alexandra Fátima Saraiva Soares - Pós-Doutorado em Direito Público pela Università degli Studi di Messina (Itália); doutorado em Saneamento, Meio Ambiente e Recursos Hídricos pela Universidade Federal de Minas Gerais (UFMG); especialização em Direito Sanitário pela Escola de Saúde Pública do Estado de Minas Gerais (ESP/MG); especialização em Direito Ambiental e Sustentabilidade (ESDHC). Professora do Centro Universitário Metodista Izabela Hendrix. Perita Ambiental no Ministério Público do Estado de Minas Gerais (MPMG), especialidade engenharia sanitária. Belo Horizonte/MG, Brasil.E-mail: alexandra@mpmg.mp.br

Luís Paulo Souza e Souza - Pós-Doutorado em Educação pela Universidade do Estado do Pará (UEPA) e em Desenvolvimento Regional pela Universidade de Santa Cruz do Sul (UNISC); doutorado em Saúde Pública pela Universidade Federal de Minas Gerais (UFMG); especialização em Saúde Coletiva pela Universidade Cândido Mendes (UCAM). Professor adjunto do Departamento Medicina do Instituto de Saúde e Biotecnologia (ISB) da Universidade Federal do Amazonas (UFAM). Coari/AM, Brasil. 